\title{
Revealing NOTCH-dependencies in synaptic targets associated with Alzheimer's disease
}

\author{
A. Perna ${ }^{a}$, S. Marathe ${ }^{b}$, R. Dreos ${ }^{c}$, L. Falquet ${ }^{d}$, H. Akarsu Egger ${ }^{d}$, L. Alberi Auber ${ }^{a, e, "}$ \\ ${ }^{\text {a }}$ Section of Medicine, Department NMS, University of Fribourg, Fribourg, Switzerland \\ ${ }^{\mathrm{b}}$ Centre for Neuroscience, Indian Institute of Science, Bangalore, India \\ ${ }^{\mathrm{c}}$ Swiss Institute of Bioinformatics (SIB), Lausanne, Switzerland \\ ${ }^{\mathrm{d}}$ Biochemistry Unit, University of Fribourg and Swiss Institute of Bioinformatics, Fribourg, Switzerland \\ ${ }^{\mathrm{e}}$ Swiss Integrative Center for Human Health, Fribourg, Switzerland
}

\section{A R T I C L E I N F O}

\section{Keywords:}

Alzheimer's disease

Hippocampus

Notch

Cell signaling

Transcription

Plasticity

\begin{abstract}
A B S T R A T
Recent studies have identified NOTCH signaling as a contributor of neurodegeneration including Alzheimer's disease' (AD) pathophysiology. As part of the efforts to understand molecular mechanisms and players involved in neurodegenerative dementia, we employed transgenic mouse models with Notch1 and Rbpjk loss of function (LOF) mutation in pyramidal neurons of the CA fields. Using RNA-seq, we have investigated the differential expression of NOTCH-dependent genes either upon environmental enrichment (EE) or upon kainic acid (KA) injury. We found a substantial genetic diversity in absence of both NOTCH1 receptor or RBPJK transcriptional activator. Among differentially expressed genes, we observed a significant upregulation of Gabra2a in both knockout models, suggesting a role for NOTCH signaling in the modulation of E/I balance. Upon excitotoxic stimulation, loss of RBPJK results in decreased expression of synaptic proteins with neuroprotective effects. We confirmed Nptx2, Npy, Pdch8, TncC as direct NOTCH1/RBPJK targets and Bdnf and Scg2 as indirect targets. Finally, we translate these findings into human entorhinal cortex containing the hippocampal region from AD patients performing targeted transcripts analysis. We observe an increased trend for $R B P J K$ and the ligand $D N E R$ starting in the mild-moderate stage of the disease with no change of NOTCH1 expression. Alongside, expression of the Notch targets Hes5 and Hey1 tend to rise in the intermediate stage of the disease and drop in severe AD. Similarly the newly discovered NOTCH targets, NPTX2, NPY, BDNF show an up-warding tendency during the mild-moderate stage, and decline in the severe phase of the disease. This study identifies NOTCH as a central signaling cascade capable of modulating synaptic transmission in response to excitatory insult through the activation of neuroprotective genes that have been associated to AD.
\end{abstract}

\section{Introduction}

Alzheimer's disease (AD) is the most frequent form of age-related neurodegenerative dementia (Alzheimers disease facts and figures, Alzheimers, 2020). Core neuropathologic features in AD include the accumulation of the protein amyloid-beta (A $\beta$ ) and the development of neurofibrillary tangles (NFT), which have been associated with neuronal degeneration and clinical symptoms of dementia (DeTure and Dickson, 2019). The AD brain is also characterized by extensive neuronal and synaptic loss in areas of the brain essential for cognitive and memory functions, such as cerebral cortex and hippocampus, often accompanied by astrogliosis (Osborn et al., 2016) and microglial activation (Hemonnot et al., 2019). Beyond the typical hallmarks of AD, synaptic dysfunction is also of major importance. In particular, changes in excitatory and inhibitory synapses releasing glutamate and GABA, respectively, have been ascribed as early contributing factors to $\mathrm{AD}$ initiation and progression (Varela et al., 2019). Signaling cascades respond to synaptic activity and contribute to network plasticity through

\footnotetext{
Abbreviations: AD, Alzheimer's Disease; NFT, Neurofibrillary Tangles; (A $\beta$ ), amyloid-beta, E/I, Excitatory/Inhibitory; LOF, Loss of Function; ChIP, Chromatin

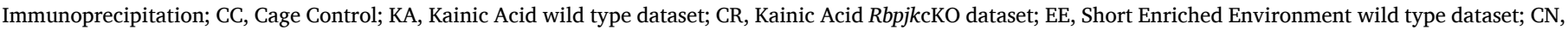

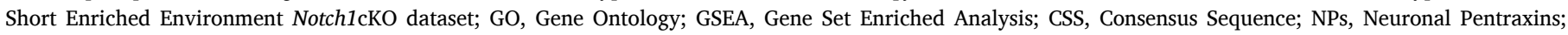
NMDAR, $N$-methyl-D-aspartate receptor.

* Correspondence to: L. Alberi Auber, Swiss Integrative Center for Human Health, Fribourg, Switzerland.

E-mail address: lavinia.alberi@unifr.ch (L.A. Auber).
} 
transcriptional and post-transcriptional regulation, influencing the biological repertoire of both neurons and glia. These adaptive changes are fundamental in supporting brain functions, such as learning and memory (Gomazkov, 2015), but can also propagate neuropathological signals contributing to progressive neurological deficits (Gadhave et al., 2020). NOTCH1 signaling, an evolutionarily conserved pathway fundamental for brain development and neural stem cell maintenance (Falo-Sanjuan and Bray, 2020), has been previously implicated in neural network function and demise. In the adult brain, NOTCH1 is expressed in pyramidal neurons of the cerebral cortex (Redmond et al., 2000) and hippocampus (Brai et al., 2015). Prevalently postsynaptic, NOTCH1 regulates spine morphology, synaptic plasticity and memory processing (Alberi et al., 2011). While some of these functions can be attributed to the interaction of NOTCH1 with NMDA and REELIN receptors (Brai et al., 2015), this signaling cascade remains largely unexplored in the context of the adult brain.

NOTCH signaling can either be canonical or non-canonical. Canonical signaling is triggered by ligand-binding, resulting in the generation of Notch Intracellular Domain (NICD). This protein's truncation associates with the transcriptional repressor RBPJK in the nucleus and leads to the recruitment of activator factors, turning RBPJK into an activator and creating a complex necessary to transcribe downstream targets. So far, only a few relevant target genes were found and widely accepted as canonical NOTCH targets (Li et al., 2012). Among others, Hes and Hey gene family members are confirmed direct targets of the NICD/RBPJK complex (Yoon and Gaiano, 2005). Non-canonical NOTCH signaling, instead, is independent of RBPJK and interacts with several pathways at either the cytoplasmic and/or nuclear level (Andersen et al., 2012). A few of the important cytoplasmic partners of NOTCH are the tyrosine kinase ABL, mTOR, PI3K, WNT/ $\beta$-CATENIN, and NF- $\kappa B$ (Alberi et al., 2013) as well as membrane receptors, APOER and NMDAR (Brai et al., 2015). It has been proposed that canonical signaling is involved in cell demise following injury (pathological condition), while non-canonical signaling plays a dominant role in synaptic plasticity (physiological condition) (Alberi et al., 2013). So far, it has been demonstrated that novel spatial navigation induces NOTCH activity in the neuronal ensemble of the hippocampus, regulating synaptic plasticity and memory formation (Alberi et al., 2011). On the other hand, hyperactivation of NOTCH signaling can cause neuronal demise following ischemic injury (Arumugam et al., 2018). In AD brains, NOTCH1 signaling appears reduced in neurons suggesting that a loss of function in NOTCH signaling may preserve neuronal survival at the expenses of synaptic plasticity contributing to the manifestation of progressive memory loss in $\mathrm{AD}$. Understanding the molecular cascade associated with NOTCH activation during neuropathological progression may help untangle the dense signaling network contributing to neurodegenerative dementia progression. In the search for NOTCH downstream targets contributing to its function, we coupled a transcriptomic approach with in silico motif analysis and ChIP validation of discovered targets upon KA-induced excitotoxicity, which mimics epileptic injury but also resembles the aberrant glutamatergic transmission (Zheng et al., 2011) observed in several neurodegenerative diseases, including AD (Wang and Reddy, 2017). Indeed, memantine, a low- to moderate- affinity NMDAR antagonist and one of the FDA-approved treatment for moderate to severe $\mathrm{AD}$, inhibits the prolonged influx of $\mathrm{Ca} 2+$ ions, preventic excitotoxic cell death (Folch et al., 2018).

To focus our search for NOTCH-dependent targets in neurons, we employed transgenic mouse models with neuron-specific deletion of either NOTCH1 receptor or RBPJK transcriptional activator to exclude glial contribution and explored the transcriptional program of the signaling either during physiological state (short enriched environment, EE) or KA-induced excitotoxicity. We show that loss of canonical and/or non-canonical signaling in pyramidal neurons of the hippocampal CA fields mainly affects the postsynaptic compartment and results in decreased glutamatergic transmission by indirect upregulation of GABAergic receptor subunit alpha 2 (Gabra2a). In contrast, we found decreased expression of synaptic proteins with neuroprotective effect, later confirmed to be under direct (Npy, Nptx2, Pcdh8) or indirect (Bdnf, Scg2) control of NOTCH1/RBPJK. These novel identified targets were validated and associated to NOTCH components in entorhinal cortices of $\mathrm{AD}$ patients with moderate or severe dementia. Collectively, these findings identify NOTCH as a promising signaling to fine-tune in order to ameliorate synaptic transmission and memory deficits that occur during early phase of neurodegenerative dementia.

\section{Materials and methods}

\subsection{Animals}

All experiments on mice were performed with permission of the local animal care committee, University of Fribourg (Protocol no. 2016_32_FR registered 01/01/2017). Male animals (2-4 months of age) were housed on a $12 \mathrm{~h}$ light-dark cycle with access to food and water ad libitum. RbpjkcKO and wild type (WT) littermate control (Rbpjkflox/flox, and CamKII::Cre) mice were obtained by crossing Rbpjkflox/flox mice (Han et al., 2002) to the CamKII::Cre (T29-1) mouse line (Tsien et al., 1996) on a C57BL6/129 background. Tissue specific Notch1cKO was obtained by crossing Nocth1 flox/flox mouse line (Radtke et al., 2000) with neuron specific CamKII::Cre (T29-1) mouse line (Tsien et al., 1996).

\subsection{Human tissue}

Frozen human entorhinal cortex tissue was generously provided by the Medical Research Council Brain Bank for Dementia Research, Oxford, UK, by Professor Thomas J. Montine from the Department of Pathology of Stanford Medicine and by the Netherlands Brain Bank (NBB). The use of human tissue has been approved by the Ethical Commission of the Brain Bank for Dementia UK (OBB443 registered 1/05/2017 and OB344 registered 1/02/2014), Stanford (Stanford IRB), and the Ethical Commission from the Canton of Fribourg and Vaud (N. 325/14). All experiments conducted on human tissue comply with the WMA Declaration of Helsinki. Individuals were divided into three groups according to post mortem pathological evaluation and Braak staging (Table 1).

\subsection{Treatments}

To investigate the KA-mediated excitotoxicity, mice were singlehoused for $30 \mathrm{~min}$ before the KA treatment. KA (Abcam, Cambridge, UK) was injected intraperitoneally (i.p.) at $25 \mathrm{mg} / \mathrm{kg}$ of body weight. This dosage was shown to induce seizures and neurodegeneration in the hippocampus (Marathe et al., 2015). Control mice were i.p. injected with an equivalent volume of vehicle $(0.9 \%$ saline). Mice were observed for $2 \mathrm{~h}$ after KA treatment and returned to their home cage. In rodents, Short Enriched Environment (EE) mimics circumstances of a stimulating and interesting living environment that is conducive to learning and cognition (Buschler and Manahan-Vaughan, 2012). To explore plasticity, mice were put in a large rat cage $(106 \mathrm{~cm}$ length, $53.34 \mathrm{~cm}$ width, and $50.8 \mathrm{~cm}$ height) with many toys, such as tubes with multiple ends, rotating wheels, objects with curious shapes and enclosed spaces for nesting. This environment provides sensory, cognitive and motor stimulation that are normally not part of standard animal housing. The

Table 1

Summary of patients' cohort.

\begin{tabular}{lllll}
\hline Group & N. patients & F:M & Age (mean $\pm S D)$ & Braak stage (N.) \\
\hline CTL & 11 & $7: 4$ & $78 \pm 8.74$ & I (4) - II (7) \\
MODERATE & 11 & $7: 4$ & $86 \pm 5.21$ & III (3) - IV (8) \\
AD & 16 & $8: 8$ & $81 \pm 8.02$ & V (6) - VI (10) \\
\hline
\end{tabular}

Values are means \pm standard deviations. CTL $=$ Age-matched controls, Moderate $=$ Moderate Alzheimer's Disease, $\mathrm{AD}=$ Severe Alzheimer's Disease. $\mathrm{F}=$ female; $\mathrm{M}=$ male. 
exposure to the environmental enriched space lasted for 7 days and mice were housed in groups of 4 in both types of cages.

\subsection{Tissue processing}

One week after environmental enrichment and $12 \mathrm{~h}$ after kainic acid treatment, mice were transcardially perfused with $0.9 \%$ sterile saline solution, brains were harvested and cut into two hemispheres. One hemisphere was dissected to collect the hippocampus and further dissected in an ice-cold saline solution to obtain the Cornu Ammonis (CA) fields, removing the dentate gyrus (Brai et al., 2015). The tissue samples were collected into Eppendorf and were flash-frozen in liquid nitrogen and stored at $-80^{\circ} \mathrm{C}$ until further use. Another hemisphere was post-fixed in 4\% PFA for 1 day, followed by immersion in 30\% sucrose at $4{ }^{\circ} \mathrm{C}$ sucrose and then embedded in an OCT block for cryosectioning at $35 \mu \mathrm{m}$ thickness (Leica, Germany) and used for histological studies.

\subsection{Immunohistochemistry}

The mice sagittal tissue sections from the anti-freezing medium were taken and then mounted onto the superfrost glass slides, air-dried for $1 \mathrm{~h}$, and washed twice in distilled water $5 \mathrm{~min}$ each. To access epitopes slides were incubated at $65^{\circ} \mathrm{C}$ (water bath) for $20 \mathrm{~min}$ in $10 \mathrm{mM}$ Sodium citrate (pH 6) containing $0.05 \%$ Tween (Preheat buffer), followed by washes in Trizma base solution (TBS) and incubation overnight with primary antibodies for GABAR2a (Novus Biologicals; NBP2-36560), NPTX2 (Abcam, ab69858) and GLUR1 (Santa Cruz Biotechnology, sc13152). After washing for 3 times with TBS, secondary fluorescent antibodies (Jackson Immuno, UK) were incubated for $3 \mathrm{~h}$ followed by washes and nuclear staining with DAPI (4,6-diamidino-2-phenylindole). After washing, slides were mounted on aqueous mounting media. Chromagen immunostainig was conducted using biotynilated secondary antibodies, followed by horse-reddish peroxidase-bound streptavidin and 3,3'-diaminobenzidine (DAB) as previously described (Marathe et al., 2015). Slides were dehydrated and mounted using resinous mounting media.

\subsection{RNA isolation and sequencing}

Total RNA was extracted using peqGOLD TriFast reagent (Peqlab, Erlangen, Germany). Isolated RNA was quantified and the quality was assessed with a Nanodrop (NanoDrop2000, Thermo Scientific, Waltham, MA, USA). Synthesis and amplification of cDNA were performed as per the Illumina TruSeq RNA protocol. RNA integrity was determined with the Fragment Analyzer 5200 (Agilent). Samples with RNA integrity number (RIN) $>8$ were used for the experiment. An input material of 1 $\mu \mathrm{g}$ of total RNA from each sample was used for library preparation. Illumina TrueSeq Combinatorial dual (CD) indexes were used during the ligation, DNA fragments enriched using the PCR to amplify the amount of DNA in the library. The quality of the libraries is determined using the Standard High sensitivity NGS Fragment analysis kit (DNF-474, 1-6000 base pair) on the Agilent Fragment analyzer (Agilent, USA), yielding approximately $260 \mathrm{bp}$ size fragments. The cDNA libraries were pooled in equivalent amounts. The libraries were denatured and diluted using standard library quantification and quality control procedures recommended as per the NextSeqprotocol. For a sequencing control, PhiX library was prepared and combined with the pooled prepared libraries. A final concentration of $1.5 \mathrm{pM}$ library was sequenced on Illumina HighSeq system to generate 20 million of $2 \times 75$ bp paired-end reads per library.

\subsection{Data analysis}

The raw RNA-seq data was first checked for its quality with FastQC. The rRNA contamination was reasonably low (5.4 to $1.1 \%$ ) for all samples. Raw data were aligned against the mouse reference genome mm10 using TopHat2 and the count matrix was built with HTSeq package on the output of TopHat2, i.e. the correctly mapped and paired reads. Approximately $80 \%$ of the reads mapped to the mouse genome. Thereafter, 17-32 million uniquely and correctly mapped reads remained for the differential analysis. Differential expression analysis was performed with Bioconductor package "DESeq2" using samples listed in Table 2 and comparison schemes explained in the experimental design (Fig. 1). The differential expression was reported in $\log 2$ fold changes (log2FC). Clustering of the samples revealed that CR3 seemed to be closer to the KA than the other two CR samples. For this reason, the following analyses were performed without including CR3 in the design.

\subsection{Statistical analysis}

For RT-PCR experiments performed on mouse specimen, statistical significance was assessed using unpaired, 2-tailed Student's $t$-test. Results (mean $\pm S E M$ ) were obtained using Excel Real Statistics plugin. Statistical significance for RT-PCR experiment performed on human tissue was assessed using One-way analysis of variance (ANOVA) with Bonferroni's correction. For both specimen, only $p$-values $<0.05$ were considered significant.

For RNA-seq experiment, the final p-value was corrected for multiple testing using the Benjamini-Hochberg method (Storey and Tibshirani, 2003) and statistically significant transcripts were chosen if adjusted pvalue (padj) $<0.05$.

Correlation analysis (Spearman's Rank) for human samples was conducted using R and significance tested using Student's $t$-test. Only significant pairs (p-value $<0.05$ ) are colored.

\subsection{Motif enrichment analysis}

The RPBJK motif matrix (PWM) was downloaded from Hocomoco database (Kulakovskiy et al., 2018) and mapped to the mouse genome using PWMscan (Ambrosini et al., 2018) with a p-value of 1e-4. Motif occurrence analysis around promoters $(2 \mathrm{~KB}$ window around annotated

Table 2

Summary of mouse samples used for RNA-seq.

\begin{tabular}{|c|c|c|c|c|}
\hline Sample & Description & $\begin{array}{l}\text { Genetic } \\
\text { background }\end{array}$ & Treatment & \#HIPs \\
\hline CC1 & $\begin{array}{l}\text { Control cage } \\
\text { replicate } 1\end{array}$ & $\begin{array}{l}\text { Wild-type } \\
\text { (C57BL/6J) }\end{array}$ & Control & 3 \\
\hline $\mathrm{CC} 2$ & $\begin{array}{l}\text { Control cage } \\
\text { replicate } 2\end{array}$ & $\begin{array}{l}\text { Wild-type } \\
\text { (C57BL/6J) }\end{array}$ & Control & 3 \\
\hline CC3 & $\begin{array}{l}\text { Control cage } \\
\text { replicate } 3\end{array}$ & $\begin{array}{l}\text { Wild-type } \\
\text { (C57BL/6J) }\end{array}$ & Control & 3 \\
\hline $\mathrm{CN} 1$ & Mutant replicate 1 & Notch1cKO & $\begin{array}{l}\text { Short enriched } \\
\text { environment }\end{array}$ & 1 \\
\hline CN2 & Mutant replicate 2 & Notch1cKO & $\begin{array}{l}\text { Short enriched } \\
\text { environment }\end{array}$ & 1 \\
\hline CN3 & Mutant replicate 3 & Notch1cKO & $\begin{array}{l}\text { Short enriched } \\
\text { environment }\end{array}$ & 1 \\
\hline CR1 & Mutant replicate 1 & RbpjkcKO & Kainate $12 \mathrm{~h}$ & 1 \\
\hline CR2 & Mutant replicate 2 & RbpjkcKO & Kainate $12 \mathrm{~h}$ & 1 \\
\hline CR3 & Mutant replicate 3 & RbpjkcKO & Kainate $12 \mathrm{~h}$ & 1 \\
\hline EE1 & $\begin{array}{l}\text { Control short-EE } \\
\text { replicate } 1\end{array}$ & $\begin{array}{l}\text { Wild-type } \\
\text { (C57BL/6J) }\end{array}$ & $\begin{array}{l}\text { Short enriched } \\
\text { environment }\end{array}$ & 3 \\
\hline EE2 & $\begin{array}{l}\text { Control short-EE } \\
\text { replicate } 2\end{array}$ & $\begin{array}{l}\text { Wild-type } \\
\text { (C57BL/6J) }\end{array}$ & $\begin{array}{l}\text { Short enriched } \\
\text { environment }\end{array}$ & 3 \\
\hline EE3 & $\begin{array}{l}\text { Control short-EE } \\
\text { replicate } 3\end{array}$ & $\begin{array}{l}\text { Wild-type } \\
\text { (C57BL/6J) }\end{array}$ & $\begin{array}{l}\text { Short enriched } \\
\text { environment }\end{array}$ & 3 \\
\hline KA1 & $\begin{array}{l}\text { Control kainate } \\
\text { replicate } 1\end{array}$ & $\begin{array}{l}\text { Wild-type } \\
\text { (C57BL/6J) }\end{array}$ & Kainate $12 \mathrm{~h}$ & 3 \\
\hline KA2 & $\begin{array}{l}\text { Control kainate } \\
\text { replicate } 2\end{array}$ & $\begin{array}{l}\text { Wild-type } \\
\text { (C57BL/6J) }\end{array}$ & Kainate $12 \mathrm{~h}$ & 3 \\
\hline KA3 & $\begin{array}{l}\text { Control kainate } \\
\text { replicate } 3\end{array}$ & $\begin{array}{l}\text { Wild-type } \\
\text { (C57BL/6J) }\end{array}$ & Kainate $12 \mathrm{~h}$ & 3 \\
\hline
\end{tabular}

$\mathrm{CC}=$ cage controls, $\mathrm{EE}=$ enriched environment, $\mathrm{KA}=$ kainic acid, $\mathrm{CN}=$ Notch1cKO exposed to EE, $\mathrm{CR}=$ RbpjkcKO with KA treatment. \#HIPs = number of hippocampi from different animals pooled together. 

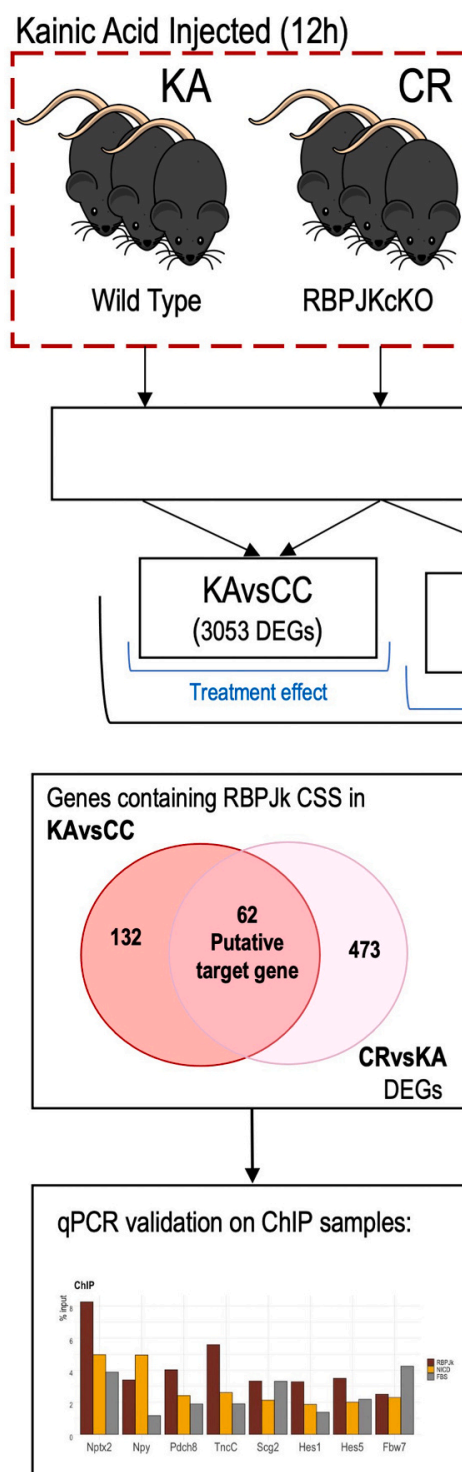

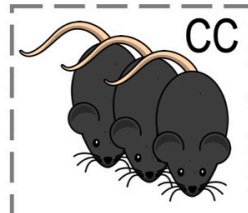

Wild Type

Cage Control
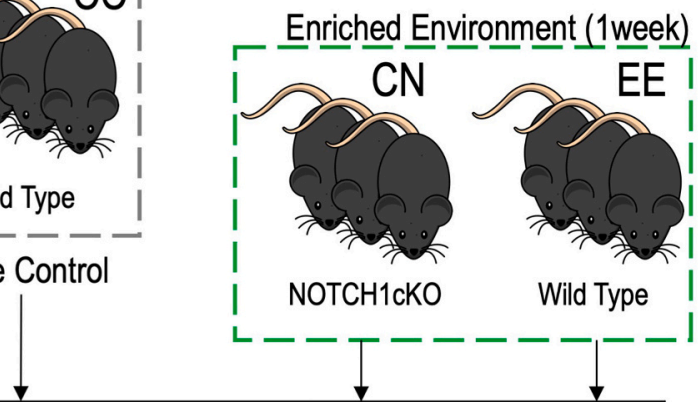

Wild Type

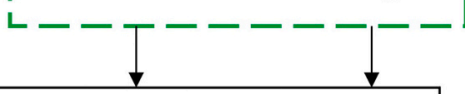

Bulk RNA-seq

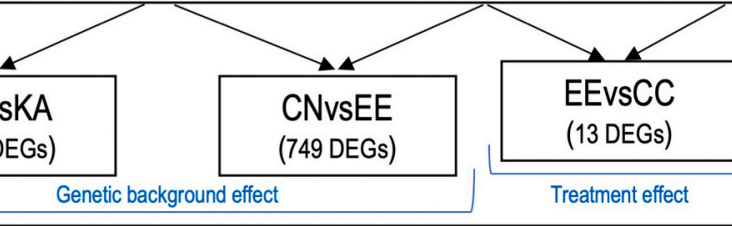

Over-representation of RBPJk CSS

in KAvsCC dataset.
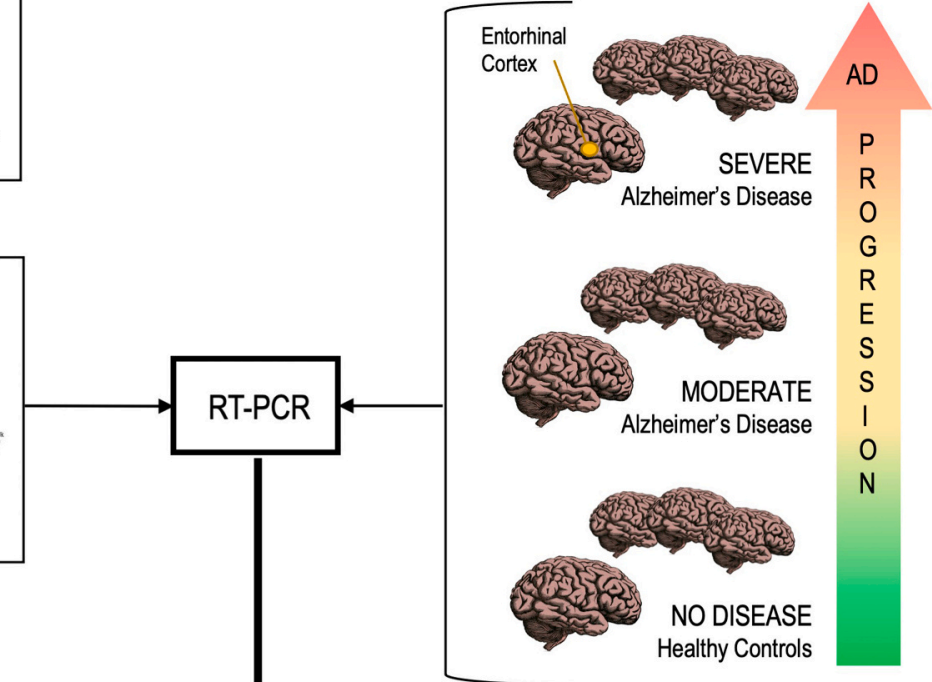

MODERATE

Alzheimer's Disease

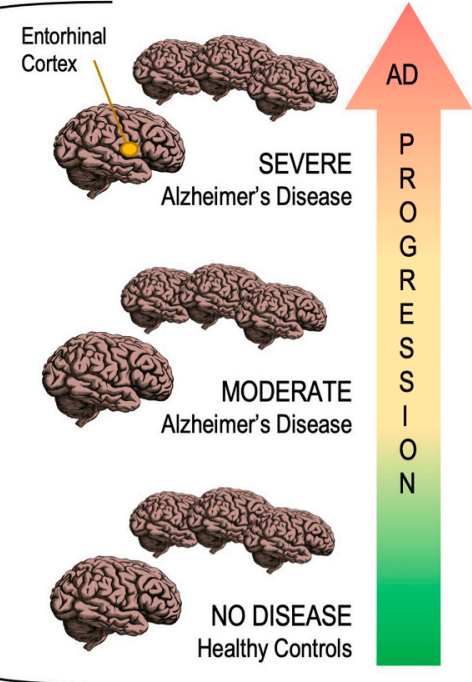

Healthy Controls

\section{Notch-related target genes involved in AD's \\ Progression.}

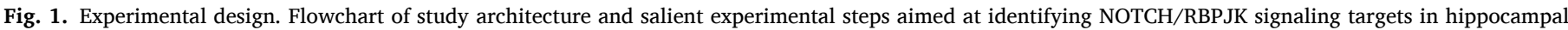

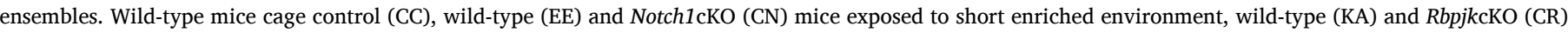
mice exposed to kainate injury;

transcription start sites) of up and down regulated genes was performed in R using the 'rtracklayer' package (Lawrence et al., 2009). These were then compared to the number of motif occurrences in the same number of promoters randomly picked from the expressed genes and repeated 500 times to generate a strong confidence interval.

\subsection{Gene ontology}

\subsubsection{GOrilla}

Gene Ontology enrichment analysis was performed with GOrilla tool (Eden et al., 2009) (http://cbl-gorilla.cs.technion.ac.il/), using two unranked gene lists (target and background). Target lists were generated for both up- and down-regulated genes belonging to the conditions $\mathrm{CR}$ versus $\mathrm{KA}$ and $\mathrm{CN}$ versus $\mathrm{EE}$. For kainic acid treatment, we chose to use 
differential expressed genes from the KA versus CC comparison as background list in order to spot just GO enrichment terms relative to the lack of RBPJK protein.

\subsubsection{REVIGO}

REViGO Bubbleplots (Supek et al., 2011) of the Enriched GO Cluster representative of up- and down-regulated genes in RbpjkcKO and Notch1cKO were generated using GOrilla terms from the enrichment analysis mentioned before. The bubbleplot shows the cluster representatives (i.e. terms remaining after the redundancy reduction) in a two dimensional space derived by applying multidimensional scaling to a matrix of the GO terms' semantic similarities (Schlicker et al., 2006). Bubble color indicates the $p$-value; size indicates the frequency of the GO term in the database (bubbles of more general terms are larger).

\subsubsection{SYNGO}

SynGO is a public knowledge-based web-tool that provides ontologies for the synapse. It relies on annotations based solely on published experimental evidence and curated by world-leading experts in synapse biology (Koopmans et al., 2019). We performed the analysis for the CR versus $\mathrm{KA}$ and $\mathrm{CN}$ versus $\mathrm{EE}$ conditions using SynGO webtools (htt ps://www.syngoportal.org/geneset.html). We looked at the gene count within the Biological Process (BP) and Cellular Component (CC) categories and we showed the analysis results using sunburst plots.

\subsection{Gene set enrichment analysis (GSEA)}

Gene Set Enrichment Analysis (Subramanian et al., 2005) (https:// www.gsea-msigdb.org/gsea/index.jsp) is a robust computational method that determines whether an a priori defined set of genes shows statistically significant, concordant differences upon KA treatment and RBPJK knockout. The analysis was performed for KA versus CC and CR versus KA datasets. Gene sets are available from Molecular Signatures DataBase (MSigDB, https://www.gsea-msigdb.org/gsea/msigdb/index. jsp) and for this analysis the HALLMARK collection of gene sets was used. Briefly, GSEA calculates an enrichment score (ES) that reflects the degree to which a gene set is overrepresented at the extremes (top or bottom) of the entire ranked list of differential expressed genes - where genes are ranked according to the expression difference (signal/noise ratio). The ES is calculated by walking down the list, increasing a running-sum statistic when it encounters a gene that is in the gene set and decreasing it when it encounters genes that are not. The enrichment score is the maximum deviation from zero encountered in the random walk; it corresponds to a weighted Kolmogorov-Smirnov-like statistic. The software then estimates the statistical significance (nominal $P$ value) of the ES and, when an entire database of gene sets is evaluated, GSEA adjusts the estimated significance level to account for multiple hypothesis testing. GSEA first normalizes the ES for each gene set to account for the size of the set, yielding a normalized enrichment score (NES). It then controls the proportion of false positives by calculating the false discovery rate (FDR) corresponding to each NES. GSEA was run according to default parameters: collapses each probe set into a single gene vector (identified by its HUGO gene symbol), permutation number $=1000$, and permutation type $=$ "gene-sets". In order to better visualize GSEA results from both analysis, we used Enrichment Map (Merico et al., 2010) (Cytoscape plugin) and to further analyze relationships between enriched genes in a given genes set, we used GeneMania (Montojo et al., 2010) that finds genes likely to share function based on their interactions.

\subsection{Chromatin immunoprecipitation (ChIP)}

For ChIP experiment we used the previously TF-ChIP protocol (Perna and Alberi, 2019). Briefly, after tissue homogenization, DNA and proteins were reversibly crosslinked with short formaldehyde incubation (1\% FA-PBS) to maintain the association of proteins with their target
DNA sequence. Cells were lysed with ionic lysis buffer and chromatin fragmented to $300 \mathrm{bp}$ using ultrasounds. The lysate was first precleaned by incubation with sepharose beads and once nonspecific DNA fragments were removed, it was incubated overnight with anti-RBPJK (Cell Signaling; \#5313) and anti-NICD (Cell Signaling; \#4147). In the negative control sample, Fetal Bovine Serum (FBS) was added. Antibody-protein-DNA complexes were then precipitated using sepharose beads. Washes and elution enriched for NOTCH signaling target genes that once purified were ready for $\mathrm{qPCR}$.

\subsection{RNA extraction and RT-PCR}

For both mouse and human samples, total RNA was extracted using peqGOLD TriFast reagent (Peqlab, Erlangen, Germany) and quantified using Qubit 3.0 Fluorometer (High sensitivity, Invitrogen). RNA integrity was assessed by capillary electrophoresis using Fragment Analyzer (Advanced Analytical AATI, United States) and just samples with RQN > 5 were selected. For RNA retrotranscription and RT-PCR it was used GoTaq 2-Step RT qPCR System (Promega) according to the manufacturer's instructions and it was performed using Mic qPCR Cycler (BioMolecular Systems, USA). Expression levels of genes of interest were determined using the CT method; the levels of the mRNAs of interest were normalized against the levels of the housekeeping gene, $\beta$-actin (mouse samples) and RPL13A (human samples).

\subsection{PCR primers}

Primer pairs for RNA-seq validation, ChIP assay and human RT-PCR are listed in Table 3. All primers were obtained from Microsynth, Switzerland.

\section{Results}

\subsection{Experimental design for NOTCH targets discovery in neurons}

To narrow down the understanding of NOTCH signaling in neurons we employed the Notch1cKO and RbpjkcKO transgenic mouse models, which lack the expression of respectively Notch1 or Rbpjk in the hippocampal CA fields (CamKII2-T291:cre) and allow to identify NOTCHdependent targets in neurons excluding any other brain cell type contribution, where NOTCH signaling is also represented. The Notch1cKO mouse model has been previously employed by our group to study the involvement of NOTCH1 in neuronal plasticity and memory/ learning processes (Alberi et al., 2011; Brai et al., 2015) and is useful in the identification of either direct canonical or non-canonical targets of the NOTCH1 receptor. The RbpjkcKO mouse model has been used to study the contribution of NOTCH canonical signaling to neurodegeneration and it is used to identify putative canonical targets of NOTCH1 in the context of neurons (Marathe et al., 2015). The previous evidence supported that NOTCH operates in a dual role with noncanonical signaling prevailing during spatial learning and canonical signaling overriding upon pathological stimuli, while in unstimulated conditions pathway activation is negligible (Alberi et al., 2011). For this reason we investigated the two transgenic models, RbpjkcKO (CR) and Notch1cKO (CN) under kainate injury (KA) and environmental enrichment (EE), respectively. Only CA fields from all mice were recovered to capture the effect of the targeted loss-of-function (LOF) in the CA regions even when using whole RNA-seq. The resulting differential expressed genes (DEGs) are interrogated based on GO analysis and direct targets are explored. The DEGs are validated using RT-PCR in the rodent model and transposed to human brains of $\mathrm{AD}$ patients with increasing severity of the disease as compared to controls (Fig. 1).

\subsection{RNA-seq analysis of NOTCH-dependent targets}

Using whole RNA-seq from CA dissected hippocampal regions, we 
Table 3

List of primers.

\begin{tabular}{|c|c|c|c|c|}
\hline Gene & Application & Species & Forward primer & Reverse primer \\
\hline Actin-b & $\begin{array}{l}\text { RNA-seq } \\
\text { validation }\end{array}$ & mouse & $\begin{array}{l}\text { GTG ACG TTG ACA } \\
\text { TCC GTA AAG A }\end{array}$ & $\begin{array}{l}\text { GCC GGA CTC } \\
\text { ATC GTA CTC C }\end{array}$ \\
\hline Bdnf & $\begin{array}{l}\text { RNA-seq } \\
\text { validation }\end{array}$ & mouse & $\begin{array}{l}\text { CCT TAC TAT GGT } \\
\text { TAT TTC ATA CTT } \\
\text { CGG TT }\end{array}$ & $\begin{array}{l}\text { TCA GCC AGT } \\
\text { GAT GCT GCT } \\
\text { GCT }\end{array}$ \\
\hline Gabra2a & $\begin{array}{l}\text { RNA-seq } \\
\text { validation }\end{array}$ & mouse & $\begin{array}{l}\text { GGA CCC AGT CAG } \\
\text { GTT GGT G }\end{array}$ & $\begin{array}{l}\text { TCC TGG TCT } \\
\text { AAG CCG ATT } \\
\text { ATC AT }\end{array}$ \\
\hline Plekha2 & $\begin{array}{l}\text { RNA-seq } \\
\text { validation }\end{array}$ & mouse & $\begin{array}{l}\text { TCG GCA GAA CCG } \\
\text { AAT CTG TG }\end{array}$ & $\begin{array}{l}\text { TCT GGG GAT } \\
\text { TGT CCA TGT } \\
\text { ACC }\end{array}$ \\
\hline Pttg1 & $\begin{array}{l}\text { RNA-seq } \\
\text { validation }\end{array}$ & mouse & $\begin{array}{l}\text { TCT GAT CCG CTG } \\
\text { TAC TCT CCT }\end{array}$ & $\begin{array}{l}\text { AGG CGG CAA } \\
\text { TTC AAC ATC CA }\end{array}$ \\
\hline Npy & ChIP & mouse & $\begin{array}{l}\text { GGT AGG GAG } \\
\text { AAG AAC CTG GGA }\end{array}$ & $\begin{array}{l}\text { CAC ACA TGC } \\
\text { AAT CTG GGT } \\
\text { TCC }\end{array}$ \\
\hline Nptx2 & ChIP & mouse & $\begin{array}{l}\text { TTC TGT CCC CAC } \\
\text { GTT CGA TG }\end{array}$ & $\begin{array}{l}\text { TCA CGG TGA } \\
\text { GTC TAG TGG GT }\end{array}$ \\
\hline Pdch8 & ChIP & mouse & $\begin{array}{l}\text { ACC CTT CAC TCT } \\
\text { TCT TCA TCG AC }\end{array}$ & $\begin{array}{l}\text { GCT TCA AAA } \\
\text { CTT GCT CTG } \\
\text { GGG }\end{array}$ \\
\hline Scg2 & ChIP & mouse & $\begin{array}{l}\text { AGT CTT GAG AAA } \\
\text { GCA GCT TAG AA }\end{array}$ & $\begin{array}{l}\text { ACA TGA ACC } \\
\text { TTT CCC ACA } \\
\text { AAG TG }\end{array}$ \\
\hline Tnc-C & ChIP & mouse & $\begin{array}{l}\text { GCT CCC TAT ATA } \\
\text { AGC CTG CCA }\end{array}$ & $\begin{array}{l}\text { AAG CCA CAA } \\
\text { CGA GTT CCC AA }\end{array}$ \\
\hline Hes5 & ChIP & mouse & $\begin{array}{l}\text { GGG AAA AGG } \\
\text { CAG CAT ATT GAG } \\
\text { GCG }\end{array}$ & $\begin{array}{l}\text { CAC GCT AAA } \\
\text { TTG CCT GTG } \\
\text { AAT TGG CG }\end{array}$ \\
\hline Hes1 & ChIP & mouse & $\begin{array}{l}\text { GGG AAA GAA } \\
\text { AGT TTG GGA AGT }\end{array}$ & $\begin{array}{l}\text { GTT ATC AGC } \\
\text { ACC AGC TCC AG }\end{array}$ \\
\hline Fbw7 & ChIP & mouse & $\begin{array}{l}\text { CTC GTC ACA TTG } \\
\text { GAG AGT GG }\end{array}$ & $\begin{array}{l}\text { CAG GAG CTT } \\
\text { GGT TTC CTC AG }\end{array}$ \\
\hline RPL13A & RT-PCR & Human & $\begin{array}{l}\text { AAA AGC GGA TGG } \\
\text { TGG TTC CT }\end{array}$ & $\begin{array}{l}\text { GCT GTC ACT } \\
\text { GCC TGG TAC TT }\end{array}$ \\
\hline NOTCH1 & RT-PCR & Human & $\begin{array}{l}\text { GAG GCG TGG CAG } \\
\text { ACT ATG C }\end{array}$ & $\begin{array}{l}\text { CTT GTA CTC } \\
\text { CGT CAG CGT GA }\end{array}$ \\
\hline RBPJK & RT-PCR & Human & $\begin{array}{l}\text { GGA TCT GGG AAT } \\
\text { CTC TAG GAA AGG }\end{array}$ & $\begin{array}{l}\text { CTC ACC AAA } \\
\text { TTT CCC AGG } \\
\text { CGA TG }\end{array}$ \\
\hline JAGGED1 & RT-PCR & Human & $\begin{array}{l}\text { GAA GCA GAA CAC } \\
\text { GGG CGT T }\end{array}$ & $\begin{array}{l}\text { CAG GTC ACG } \\
\text { CGG ATC TGA T }\end{array}$ \\
\hline DNER & RT-PCR & Human & $\begin{array}{l}\text { TGC AGG GAC CTC } \\
\text { GTT AAT GG }\end{array}$ & $\begin{array}{l}\text { AAT GTC GCA } \\
\text { CTC TTC ACC } \\
\text { TGT }\end{array}$ \\
\hline HES5 & RT-PCR & Human & $\begin{array}{l}\text { TCT CCT CGT CGC } \\
\text { CTG TTC }\end{array}$ & $\begin{array}{l}\text { CCA CGA GTA } \\
\text { GCC TTC GCT } \\
\text { GTA G }\end{array}$ \\
\hline HES1 & RT-PCR & Human & $\begin{array}{l}\text { TCA ACA CGA CAC } \\
\text { CGG ATA AAC }\end{array}$ & $\begin{array}{l}\text { GCC GCG AGC } \\
\text { TAT CTT TCT } \\
\text { TCA }\end{array}$ \\
\hline HEY1 & RT-PCR & Human & $\begin{array}{l}\text { ACG AGA ATG GAA } \\
\text { ACT TGA GTT }\end{array}$ & $\begin{array}{l}\text { AAC TCC GAT } \\
\text { AGT CCA TAG } \\
\text { CAA }\end{array}$ \\
\hline MAP2 & RT-PCR & Human & $\begin{array}{l}\text { CTG CTT TAC AGG } \\
\text { GTA GCA CAA }\end{array}$ & $\begin{array}{l}\text { TTG AGT ATG } \\
\text { GCA AAC GGT } \\
\text { CTG }\end{array}$ \\
\hline IBA1 & RT-PCR & Human & $\begin{array}{l}\text { CTC AGG ATG ATG } \\
\text { CTG GGC AAG AGA }\end{array}$ & $\begin{array}{l}\text { AGC CCC TTC } \\
\text { AAT CCC ATC } \\
\text { ATC CCT }\end{array}$ \\
\hline GFAP & RT-PCR & Human & $\begin{array}{l}\text { CCT CTC CCT GGC } \\
\text { TCG AAT G }\end{array}$ & $\begin{array}{l}\text { GGA AGC GAA } \\
\text { CCT TCT CGA } \\
\text { TGT A }\end{array}$ \\
\hline BDNF & RT-PCR & Human & $\begin{array}{l}\text { TAA CGG CGG CAG } \\
\text { ACA AAA AGA }\end{array}$ & $\begin{array}{l}\text { TGC ACT TGG } \\
\text { TCT CGT AGA } \\
\text { AGT AT }\end{array}$ \\
\hline GABRA2a & RT-PCR & Human & $\begin{array}{l}\text { GTT CAA GCT GAA } \\
\text { TGC CCA AT }\end{array}$ & $\begin{array}{l}\text { ACC TAG AGC } \\
\text { CAT CAG GAG CA }\end{array}$ \\
\hline NPTX2 & RT-PCR & Human & $\begin{array}{l}\text { TGA TCC TTG GAC } \\
\text { AAG AGC AG }\end{array}$ & $\begin{array}{l}\text { ATT TCT TGT } \\
\text { GCG CGA AGG }\end{array}$ \\
\hline NPY & RT-PCR & Human & $\begin{array}{l}\text { GGA AAA CGA TCC } \\
\text { AGC CCA GA }\end{array}$ & $\begin{array}{l}\text { CAG GGT CTT } \\
\text { CAA GCC GAG TT }\end{array}$ \\
\hline ANXA2 & RT-PCR & Human & $\begin{array}{l}\text { GCC ATC AAG ACC } \\
\text { AAA GGT GT }\end{array}$ & $\begin{array}{l}\text { TCA GTG CTG } \\
\text { ATG CAA GTT CC }\end{array}$ \\
\hline PLEKHA2 & RT-PCR & Human & $\begin{array}{l}\text { GGT GAG CAT AGC } \\
\text { TAC CCC AA }\end{array}$ & $\begin{array}{l}\text { CCA CCT TTG } \\
\text { GGA ACG GTG AT }\end{array}$ \\
\hline
\end{tabular}

have investigated the differential expression of NOTCH-dependent genes either upon EE or KA. For data analysis, different comparison schemes were carried out (Fig. 1): Comparison of the effect of EE or KA with normative conditions (CC) allows determining treatmentdependent genetic changes. After $12 \mathrm{~h}$ from KA induction, we observe a significant change in gene expression: 3053 genes are differentially expressed, padj $<0.05$ and 136 DEGs have a 2 fold change cutoff with the majority of the genes in this subgroup being upregulated, $89 \%$ (Fig. 2A). The synaptic gene ontology (SynGO) analysis of the upregulated DEGs shows an enrichment in 7 postsynaptic genes of the postsynaptic density (Adra2c, Gsg1l, Ptprf, Sorcs3, Itga5, Slc6a8 and Nptx2) and 4 pre-synaptic genes regulating presynaptic vesicle sorting ( $S c g 2$, Rab26) and synaptic membrane (Nptx2 and Sv2c) (Supplementary Fig. 1A). Notch1 is also significantly but more modestly upregulated (Log2 fold change $=0.56)$ to a similar extent as its canonical target Hes1 (Log2 fold change $=0.66$ ) and associated NOTCH-gene Bdnf (Log2 fold change $=0.69$ ). While its other canonical target Hes5 appears downregulated (Log2 fold change $=-0.89$ ). In line with previous research, KA administration induces aberrant regulation of genes involved in neurotransmission like Secretogranin II (Scg2), shown to increase expression in rat hippocampus following KA intoxication (Mahata et al., 1992), Neuropeptide Y, Npy and its receptors Npy1r and Npy2r, known to be involved in seizure modulation (Lin et al., 2006) and Huntingtinassociated protein 1 (Hap1). We also observe robust upregulation of genes involved in reactive astrogliosis, like glial fibrillary acidic protein Gfap (Otani et al., 2003) and the proinflammatory adhesion molecule Cd44 (Bausch, 2006). Excitotoxicity induced also general upregulation of NOTCH signaling components, which is repressed by loss of RBPJK, supporting the involvement of NOTCH signaling in neuronal demise after excitotoxicity (Marathe et al., 2015). On the other hand, one week of EE causes only subtle changes (13 DEGs, padj $<0.05$, with Log2 fold changes between 0.2 and 0.4 ). 5 neuronal plasticity genes appear slightly upregulated (Ier5, Nptx2, Egr3, Homer1) and the rest of the DEGs belong to glio-vascular homoeostasis (Fig. 2B). We have previously demonstrated that the loss of RBPJK in hippocampal neurons is neuroprotective and we have identified cell-cycle reentry as one of the putative neurodegenerative mechanisms regulated by NOTCH/RBPJK signaling (Marathe et al., 2015). To further expand our understanding of the gene targets contributed by the loss of canonical NOTCH signaling under kainate stimulus, KA-injected RbpjkcKO (CR) mice were compared to KA mice after $12 \mathrm{~h}$ of challenge. Of the 461 significant DEGs with a padj $<0.05,116$ DEGs show an equal or larger 2-fold cutoff with a concentration in downregulated hits (79\%, Fig. 2C). This is in opposition to large gene upregulation upon KA treatment (Fig. 2A) and supports that NOTCH/RBPJK signaling is a transcriptional activator in condition of injury (Fig. 2C). Statistical over-representation analysis of GOs using the REVIGO tools for cellular components on the upregulated genes, shows a localized enrichment for dendrites, neuronal membrane parts and GABAergic synapse while downregulated hits are more concentrated in the extracellular space besides conserving a synaptic localization (Supplementary Fig. 2A). SYNGO analysis represented as sunburst chart illustrates the synaptic terms occurrence and confirms the synaptic identity of the differentially expressed hits with a concentration of postsynaptic genes (Supplementary Fig. 2B) supporting the specificity of the RbpjkcKO model for studying NOTCH-dependent processes in neurons. Among differentially expressed genes, Npy, the synaptic protein Neuronal Pentraxin II (Nptx2), the lipid metabolism mediator Plekha2 and $B d n f$ neurotrophin which are upregulated after KA administration (Fig. 2A) are repressed in absence of RBPJK (Fig. 2C), raising the idea that these genes may be under either direct or indirect control of the signaling. Further elucidating the role of NOTCH1 in memory processing, we have investigated the contribution of NOTCH1 in condition of increased synaptic plasticity and compared the Notch1 $\mathrm{cKO}(\mathrm{CN})$ to mice exposed to short environmental enrichment (EE). While the EE paradigm did not elicit substantial changes (Fig. 2B), the comparison shows 749 DEG with a padj $<0.05$ and a smaller proportion of genes, 48 , with a 
2-fold change cutoff for the large part downregulated (65\%), reflecting mostly the NOTCH1 loss of function (Fig. 2D). GO analysis using the REVIGO tools for cellular components on the upregulated genes, shows an enrichment for neuronal and synaptic components as well ribosomal subunits, while downregulated genes are concentrated in the extracellular space and synapse (Supplementary Fig. 2C). To confirm the topology of the gene hits, SynGO reveals that also in case of Notch1 loss in neurons, the majority of the hits are localized postsynaptically and distributed between ribosomal genes and neurotransmitter transmembrane receptors (Supplementary Fig. 2D). NOTCH1 LOF in hippocampal neurons reduced expression of Insulin degrading enzyme (Ide), the synaptic vesicle protein Synaptoporin (Synpr) and upregulated the synaptic anchoring Homer protein homolog 1 (Homer1) and Perilipin 4 (Plin4), coating protein of lipid droplets. Furthermore lack of NOTCH1 receptor in EE condition induces enrichment in GABAergic signaling through upregulation of Plekha2 and the GABAergic Receptor 2 (Gabra2), similarly to the loss of RBPJK (Fig. 2C and D). To validate the ablation of NOTCH1 and RBPJK components in the respective conditional KO mice, we performed RT-PCR on whole hippocampal tissue ( $n=4$ for each genotype/condition) and confirmed that Notch1 is significantly but moderately reduced $(30 \%, p<0.001)$ in Notch1cKO (Fig. 2E) suggesting either a partial deletion or an increased expression of Notch1 in other cells than neurons as previously observed (Alberi et al., 2011). On the other hand Rbpjk is significantly reduced $(60 \%$, $p<0.05)$ in the RbpjkcKO reflecting the loss of canonical signaling (Fig. 2E). To narrow the understanding of the contribution of transcriptional versus default (canonical and non-canonical) NOTCH signaling, we have utilized literature-based gene pools for neuronal plasticity and injury. Overall the KA challenge induces the expression of the selected hits, while in absence of Rbpjk directionality of expression is overall reversed with a conserved trend also in the Notch1cKO for the transcription factor Atf4 and Sod3 (Fig. 2F). Further dissecting the contribution of NOTCH1 and RBPJK, selected gene-sets for excitatory neurons reveals a NOTCH-canonical repression of Nptx2, Bdnf and Grm2, accompanied by an activation of the inhibitory component, Gabra2a, also present in the Notch1cKO (Fig. 2G). Overall, the absence of $R b p j k$ reveals a more robust effect on gene expression both based on the ubiquitous deletion of NOTCH signaling and the KA treatment condition. Overall the RNA-seq analysis using the LOF model for NOTCH1 and RBPJK supports the bimodal role of NOTCH in memory formation and the neuronal response to excitotoxic insult.

\subsection{Validation of selected NOTCH targets}

Comparative gene set enrichment analysis (GSEA) of the DEGs in KA vs CC and CR vs KA shows a strong complementarity of the hallmarked pathways of inflammation (IL-2-Stat4 and MAPK-IL-6-JAK-STAT3), hypoxia (TNFA-NFKB) and apoptosis (p53 and G2M) (Fig. 3A) confirming that the absence of RBPJK in neurons has an instrumental effects on neuronal plasticity and viability. To confirm the reproducibility of the RNA-seq analysis, we have performed RT-PCR ( $n=4$ for each genotype/condition) validation of selected hits with a 2-fold differential expression change with neuronal (Gabra2a and Bdnf) and non-neuronal identity (Plekha2 and Pttg1). We confirmed a significant downregulation of $B d n f$ in absence of Rbpjk under KA treatment $(63 \%, p=0.03$ ) (Fig. 3B), Plekha2 and Pttg1 were comparably slightly repressed in absence of Notch1 (25\%, $p=0.04$ and $p=0.01$ ) (Fig. 3C), while Gabra2a tends to increase in absence of RBPJK ( 3.35 folds, $p=0.06$ ) as well as Notch1 (1.5 folds, $p<0.001$ ) (Fig. 3B and C). Gabra2a upregulation was further confirmed at the protein level by immunohistochemistry of GABRA2 subunit alpha in RbpjkcKO model and upon KA-mediated excitotoxicity, while in Notch1cKO GABRA2A protein levels are not significantly different than wild-type controls (Fig. 3D). The RT-PCR analysis confirms the reproducibility of the RNA-seq performed and evidences a direct modulation of canonical NOTCH1/RBPJK signaling on E/I balance.

\subsection{RBPJK-dependent target genes}

To further explore direct NOTCH target genes in adult neurons, we interrogated each dataset for the occurrence of the RBPJK Consensus Sequence (CSS) CGTGGGAA bound specifically by the transcription factor RBPJK (Tun et al., 1994). RBPJK is typically engaged in a transcriptional repressor complex, that is transformed from a repressor to an activator complex when NOTCH is activated/cleaved and the intracellular domain (NICD) enters the nucleus. NICD binds to RBPJK, displacing the repressive cofactors bound to RBPJK and recruits a transcriptional activator complex, which initiates transcription of its target genes (Kopan and Ilagan, 2009). We compared the RBPJK CSS occurrence with the one of random motifs commonly found at promoters ( $n=500)$. Among up-regulated genes, we found that KA-induced excitotoxicity enriches for genes carrying RBPJK CSS in their promoter. These genes remain low in EE and, as expected for LOF models, RBPJK motif doesn't appear enriched either in Notch1cKO (CN) nor in RbpjkcKO (CR) (Fig. 4A). Intersection of the 132 RBPJK targets found upon KA treatment with the 472 DEGs in RbpjkcKO, identifies 62 genes that represent putative NOTCH canonical target genes activated upon excitotoxicity (Fig. 4B). The heatmap shows that these putative targets have opposite expression's trends in RbpjkcKO, with the majority of them being downregulated in absence of RBPJK (Fig. 4C). Interestingly, Bdnf, Gabra2 and Plekha2, whose expression is upregulated in knockout models, did not carry RBPJK CSS, supporting the idea that these genes are indirect targets of NOTCH signaling. Taken together, these results confirm that activation of NOTCH/RBPJK signaling in neurons upon KA injury exerts a strong transcriptional drive, and that lack of Rbpjk blocks the transcriptional program with an overall neuroprotective effect (Marathe et al., 2015; Arumugam et al., 2011). To validate the in silico identified target genes, we combined transcriptome analysis with Chromatin Immunoprecipitation (ChIP) assay using RBPJK, NICD specific antibody and FBS as negative control (Perna and Alberi, 2019). The experiment was performed for canonical targets (Hes1 and Hes5) and selected putative targets with known association with $\mathrm{AD}$ (Npy, Nptx2, Pdch8, Scg2 and Tnc-C), using Fbw7 as a negative control. Results confirm the direct binding of RBPJK to the promoter region. Precipitation with NICD results less efficiently but shows the same trend (Fig. 5A). From the list of direct targets, the strongest bound is Nptx2, an early immediate gene in hippocampal ensembles, with synaptic scaling function and a driver of cognitive decline in AD (Xiao et al., 2017). Among the putative targets, we selected Nptx2, Npy, Pdch8 and Tnc-C which are implicated in synaptic plasticity and have been functionally associated with $\mathrm{AD}$ pathophysiology to confirm the dependencies to canonical NOTCH-RBPJK signaling. We confirmed using RT-PCR $(n=4$ for each genotype/condition) that in RbpjkcKO, Nptx2 and Tnc-C are significantly reduced while Npy and $P d c h 8$ are only subtly changed (Fig. 5B). The loss of Nptx2 in RbpjkcKO was confirmed using fluorescent immunohistochemistry on hippocampal sections [Integrated Density (IntDen) of wt $=96.4 \pm 18.3$, IntDen of $R b p j k c K O=27.35 \pm 1.6$, $p=0.02$; Fig. $5 \mathrm{C}]$, which resulted in a comparable repression of GLUR1 (Fig. 5D). The present data corroborates the role of NOTCH as an important driver of synaptic plasticity in neurons with direct associations with $\mathrm{AD}$ neuronal networks' dysfunction.

\subsection{Validation of NOTCH signaling targets on AD specimen}

The RNA-seq in the rodent model identified a panel of direct and indirect target genes downstream NOTCH signaling, with a potential role in neurodegenerative processes associated with $\mathrm{AD}$. We explored the expression profiles of NOTCH signaling components and the novel targets in post-mortem entorhinal cortices from a multicentric cohort of subjects with mild-moderate $\mathrm{AD}(n=11)$, severe $\mathrm{AD}(n=16)$, representing the most common form of neurodegenerative dementia. Specimens from the clinical cohorts are compared to age-matched controls (CTL, $\mathrm{n}=11$ ). Molecular analyses in humans evidences a great 
A)

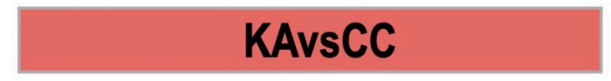

$$
\text { Pmepà1 }
$$

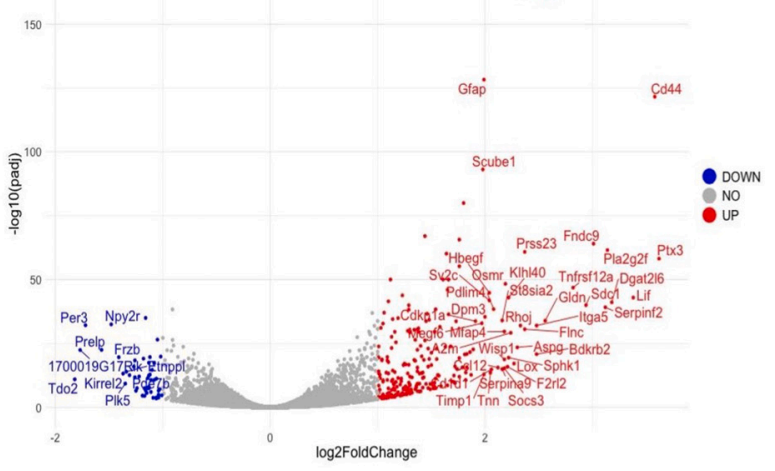

C)
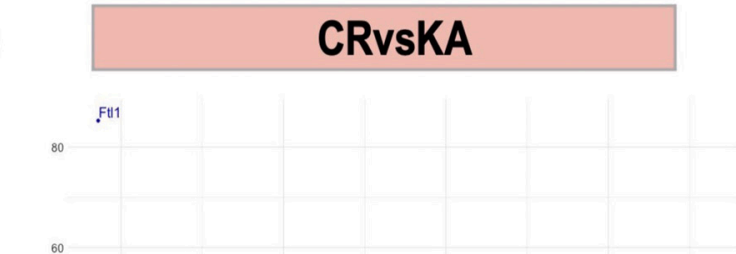

E)

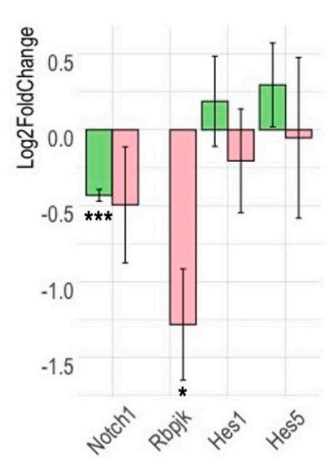

$\square$ NOTCH1CKO_SEE $\square$ RBPJKCKO_KA
B)

\section{EEvsCC}

D)
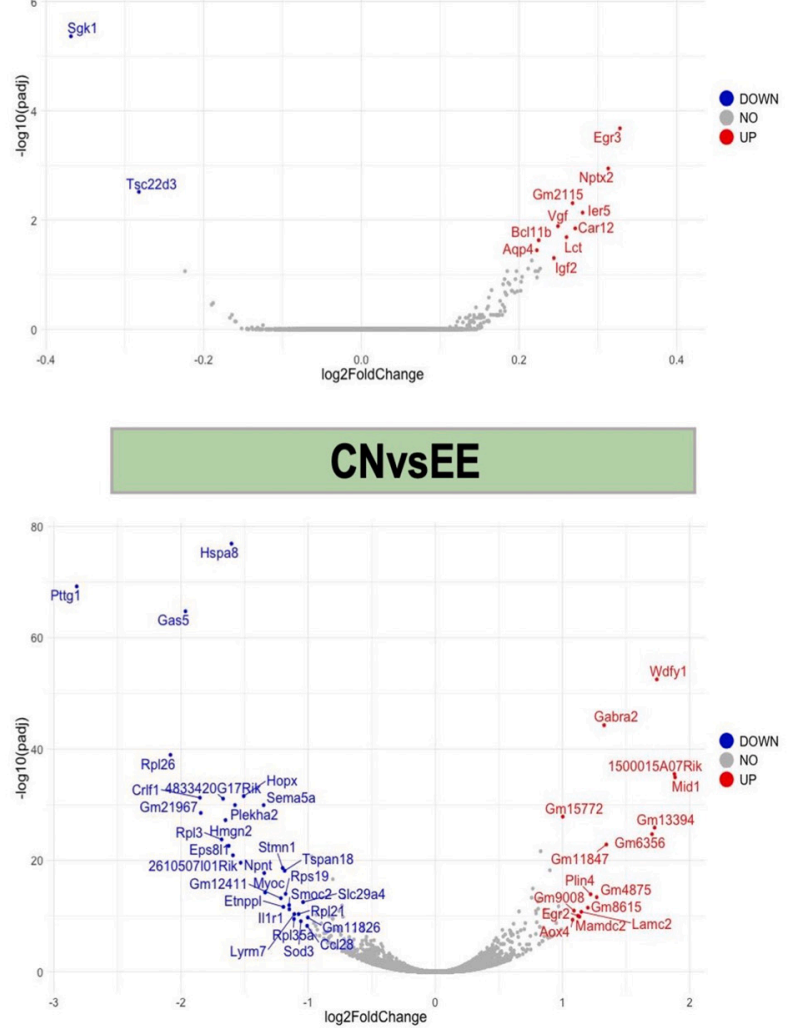

G)

F)

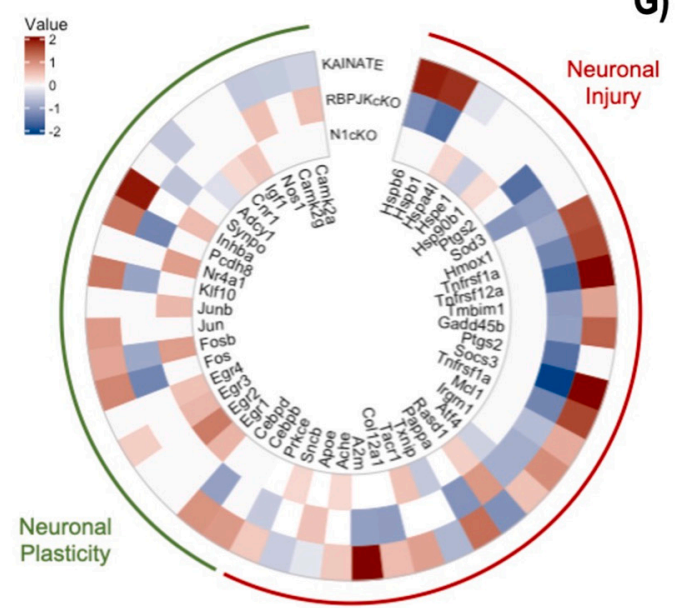

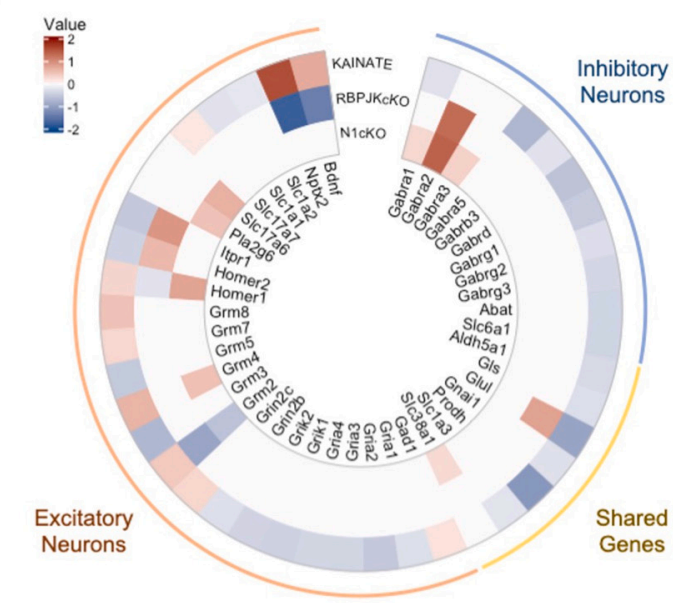

Fig. 2. RNA-seq analysis of mice lacking either RBPJK or NOTCH1 in hippocampal neurons. Volcano plots with log2 fold change (X-axis) and -log10 $p$-value (Y-axis) of differential expressed genes from comparison of A) KA-injected (KA) and wild-type (CC) mice, B) mice exposed to an enriched environment (EE) for 1 week and wild-type mice (CC), C) Rbpjk conditional knockout (CR) and wild-type mice (KA), both KA-injected, D) Notch1 conditional knockout (CN) and wild type mice (EE), both sacrificed 1 week after exposure to the enriched environment. E) RT-PCR analysis of NOTCH1 signaling components in RbpjkcKO mice upon excitotoxicity as compared to KA and Notch1cKO mice under enriched environment as compared to EE (Student's $t$-test, $n=4$ /group). Circular heatmaps show differential expression values (Log2FC) of genes within kainate (KAvsCC), RBPJKcKO (CRvsKA) and N1cKO (CNvsEE) datasets, involved in F)) neuronal plasticity/neuronal injury and G) excitatory/inhibitory neurons. *** indicates $P$ values $<0.001$ and * is for pvalue $<0,05$. Error bars represent standard error of the mean (SE). 
A)

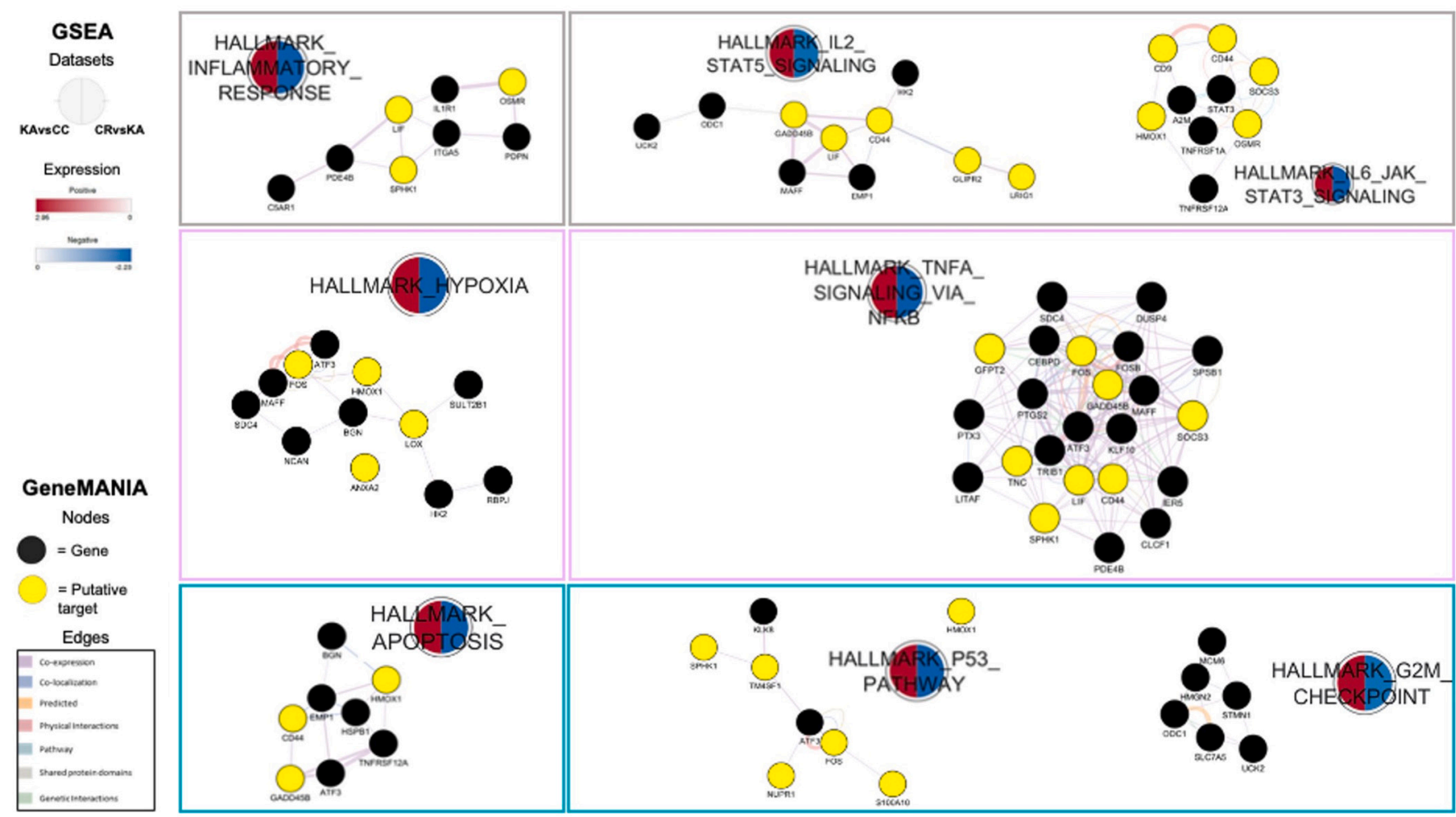

B)

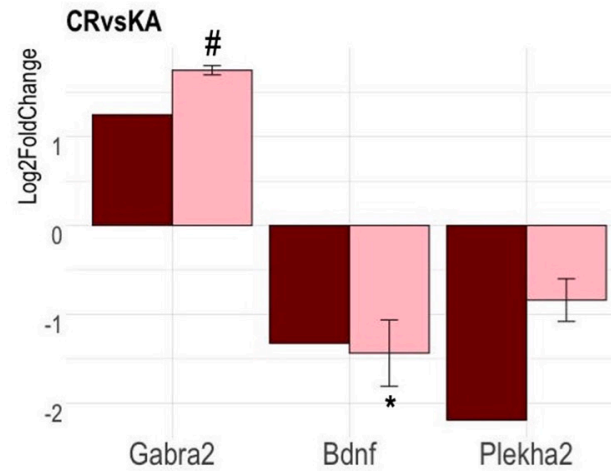

C)

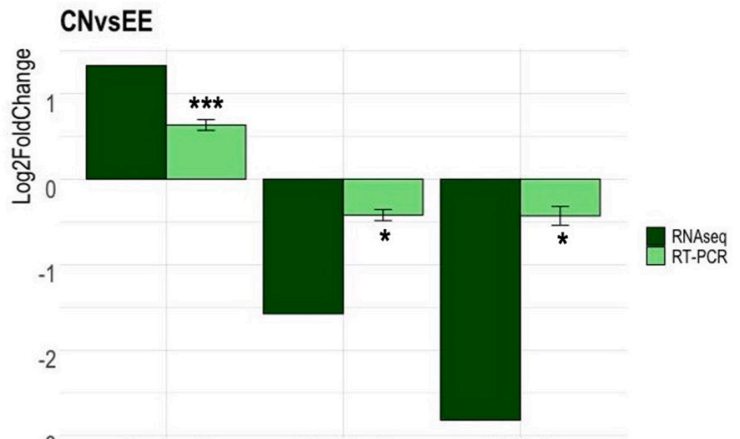

Gabra2 Plekha2 Pttg1

D)
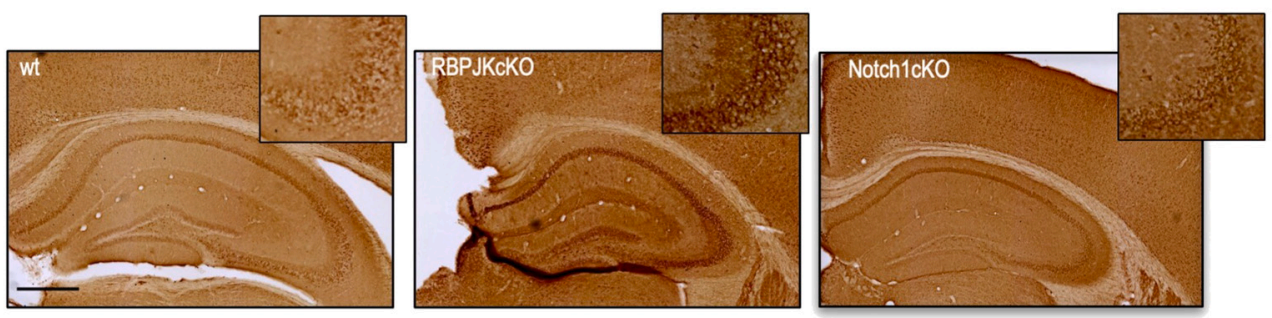

Fig. 3. Transcriptional changes in Notch1cKO mice after SEE and RbpjkcKO mice KA-injected A) Gene Set Enrichment Analysis (GSEA) using Hallmark gene set from MSigDB Collections highlights three main processes (Inflammatory response, Hypoxia and Apoptosis) affected by the absence of RBPJk, following neuroexcitotoxicity (CRvsKA). GeneMania visualizes the network of interaction of genes within the processes. RNA-seq validation using RT-PCR for up- and down-regulated genes in B) CRvsKA comparison and C) CNvsEE comparison (Student's $t$-test, $n=4$ /group). D) Immunoistochemistry of Gabra2 $\alpha$ in hippocampal sections of wild-type (wt) mice, RbpjkcKO mice and Notch1cKO mice shows increase of GABRA2A protein level in absence of RBPJk and more marginally in Notch1cKO. *** indicates $p$ values $<$ $0.001, *$ is for pvalue $<0,05$, and \# indicates $p$-value $<0.07$. Error bars represent standard error of the mean (SE). Scale bar in D is $500 \mu \mathrm{m}$. 
A)

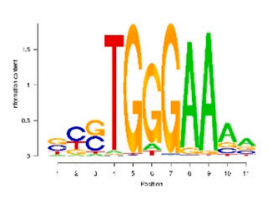

C)

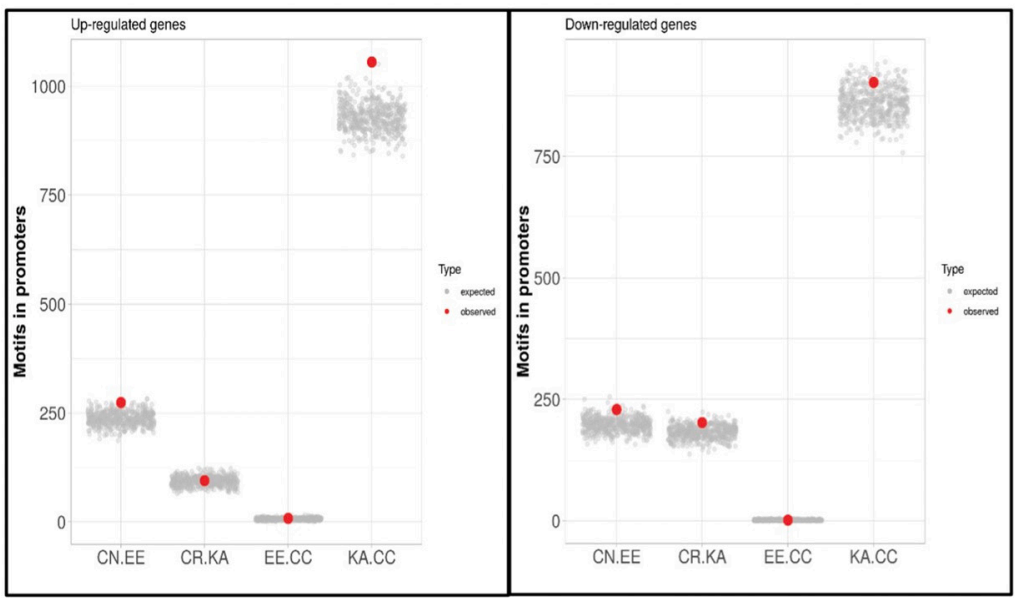

B)

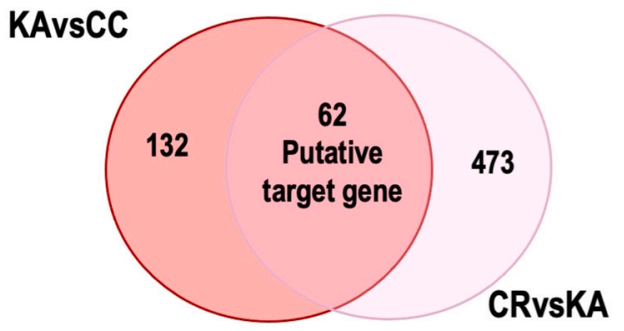

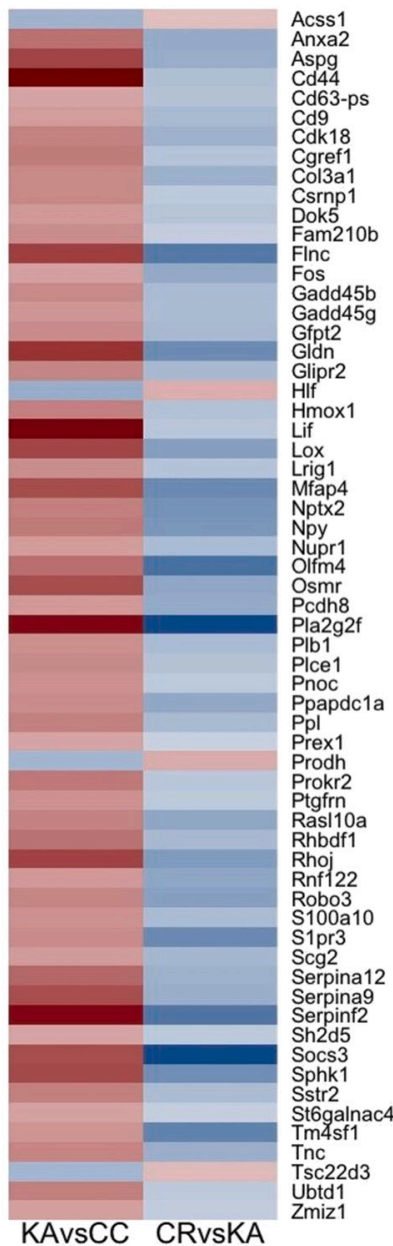
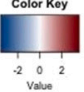
A)

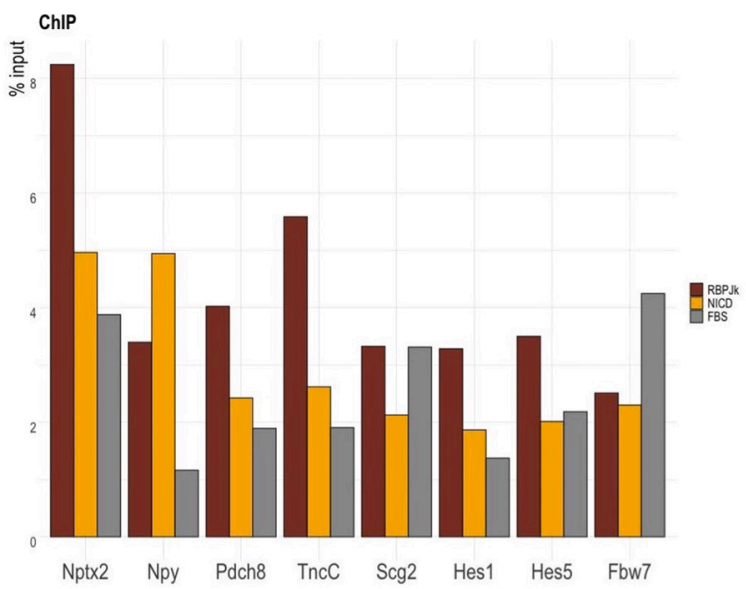

C)

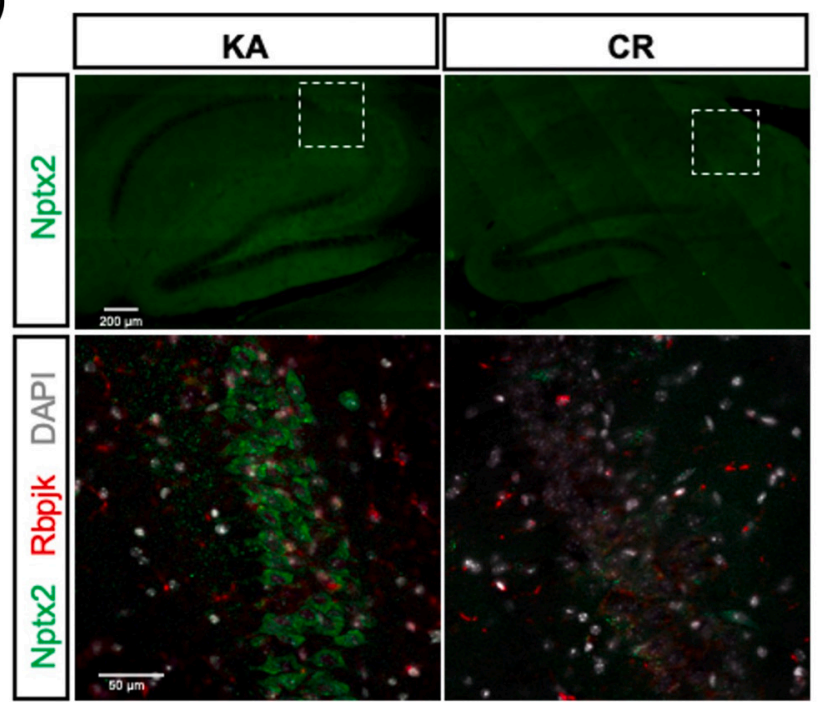

B)

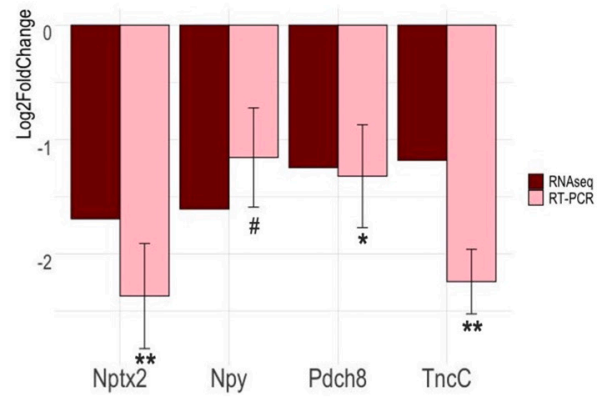

D)

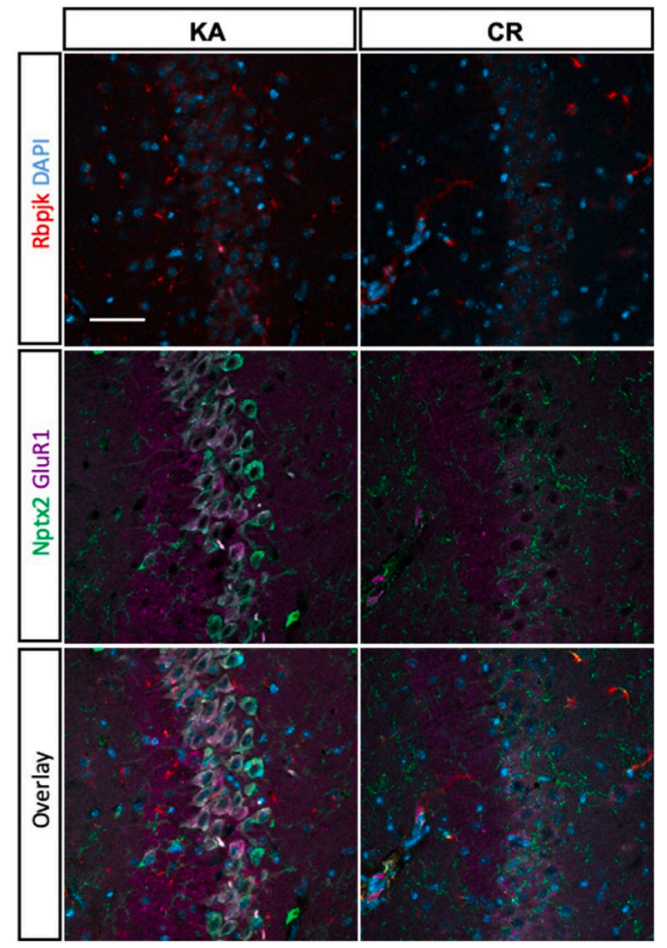

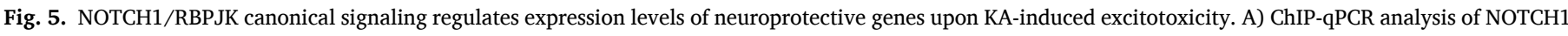

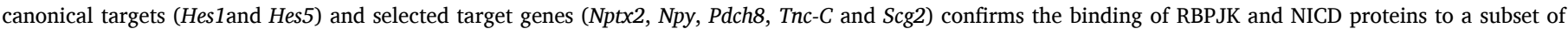

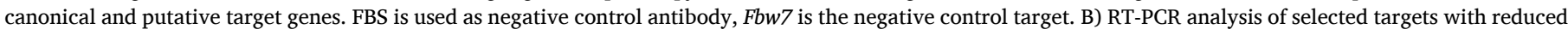

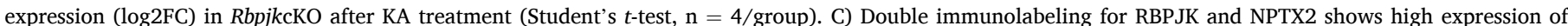

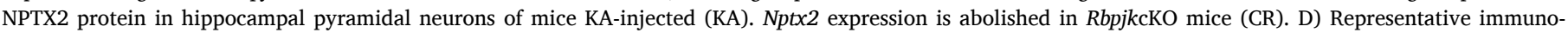

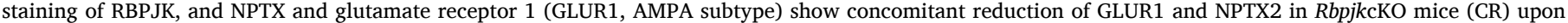
neuroexcitotoxicity. ${ }^{* *}$ indicates pvalue $<0.01$, * is for pvalue $<0.05$, and \# indicates $p$-value $<0.07$. Error bars represent standard error of the mean (SE).

Jagged1 affect spatial learning and memory by interfering with NMDAR transmission through a non-transcriptional mechanism (Brai et al., 2015). As an additional signaling modality, loss of Rbpjk affects memory formation by increasing the inhibitory tone through GAT2 and BGT1 repression and likely through this mechanism confers neuroprotection following epileptic injury (Liu et al., 2015).

Although how NOTCH LOF plays out in the sustaining neuronal network plasticity and homeostasis can be only explained using an omics discovery approach and neuronal specific mutants as employed in this study.

In particular, in this study we have used two conditions, environmental enrichment and epileptogenic kainic acid injection, in which NOTCH signaling is induced, representing surrogate conditions for physiological and pathological brain activity. Kainic acid has been extensively used in in-vitro and in-vivo to investigate glutamate excitotoxicity a phenomenon not only present in epilepsy, but also in Alzheimer's disease in an around amyloid-beta plaques, and stroke. We have confirmed that the majority of genetic changes influenced by NOTCH are postsynaptic, affirming its topological prevalence (Brai et al., 2015). In absence of both canonical and non-canonical signaling and upon different treatment conditions, GABRA2A mRNA and protein level increase in hippocampal neurons suggesting an increase in inhibitory drive in absence of NOTCH, which is aligned with the observed increased inhibition in RbpjkcKO mice (Liu et al., 2015). Also, Plekha2, a lipid binding protein, which is positively associated with epilepsy (Sprissler et al., 2017) is downregulated in both Notch1cKO and RbpjkcKO mice, further supporting a downscaling of synaptic tone. An additional evidence for a direct effect on synaptic plasticity in RBPJK LOF, comes from the reduction in Bdnf already identified as an associated target (Brai et al., 2015) 

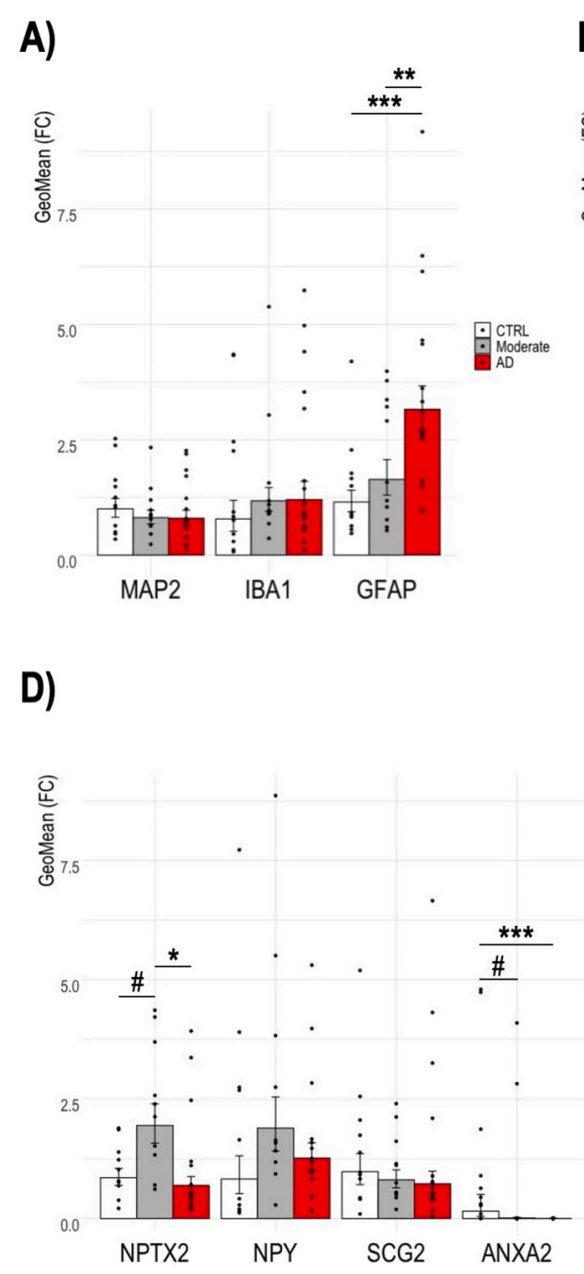
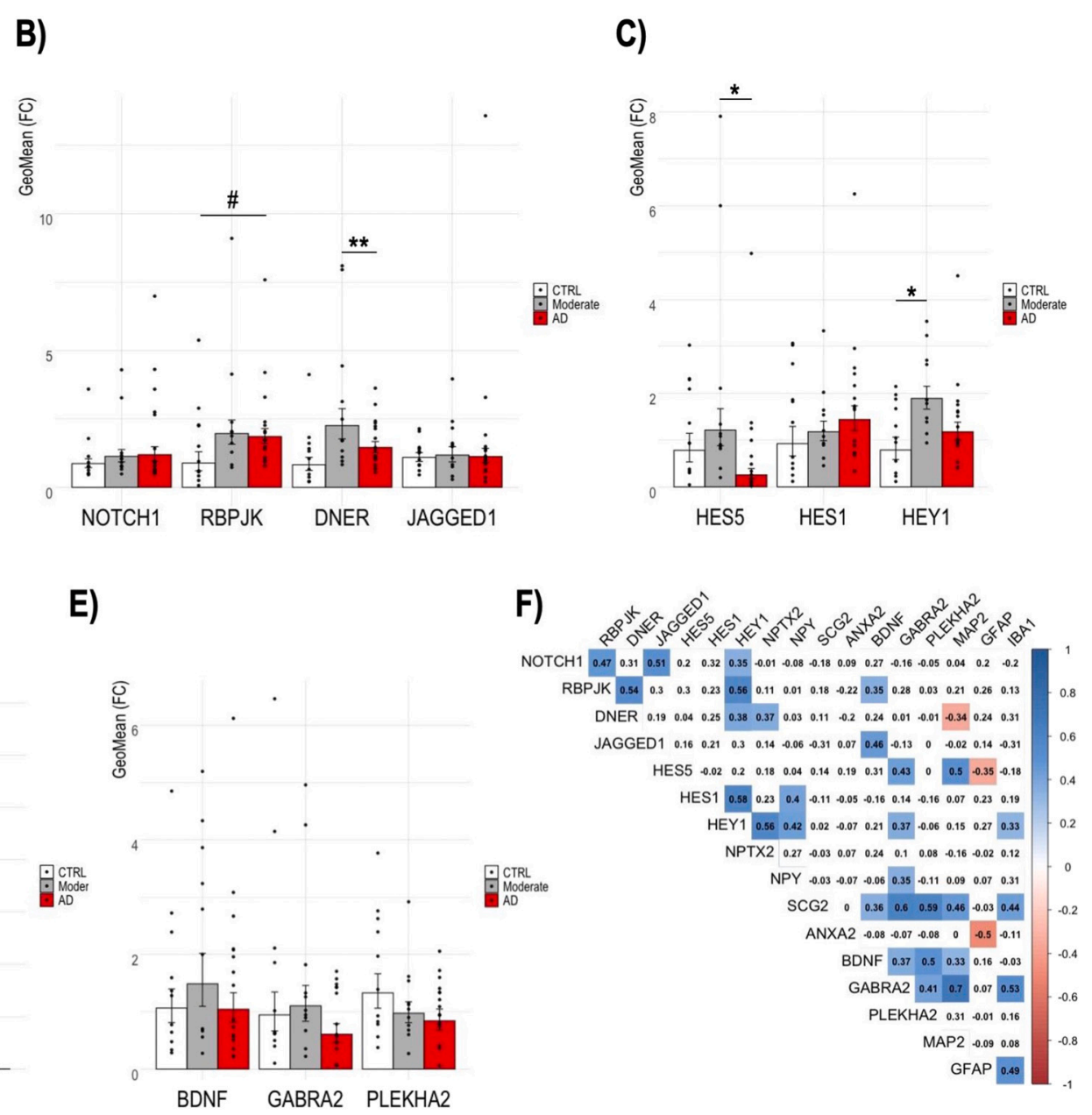

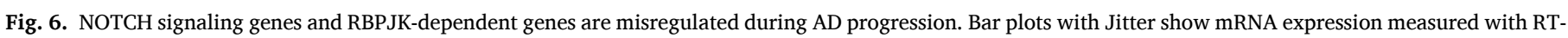

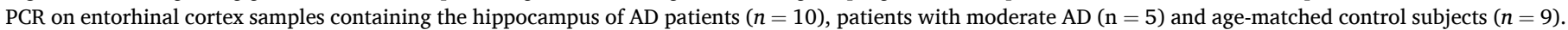

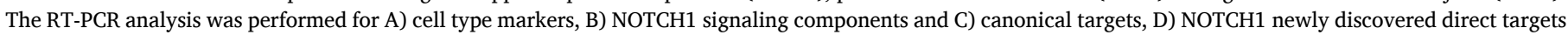

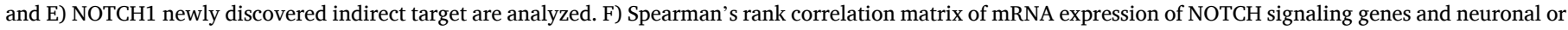

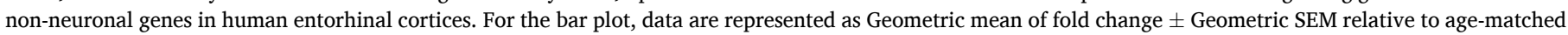

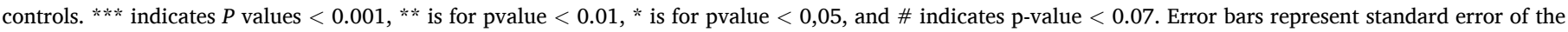
mean (SE).

Upon kainate treatment, mimicking ectopic excitotoxicity, we observe a rise in CSS binding motifs in the differential expressed genes, emphasizing the notion that canonical signaling is strongly induced upon glutamatergic injury (Alberi et al., 2013). Of those genes, 62 have inverse directionality in the RbpjkcKO hippocampi, further confirming their identity as legitimate transcriptional NOTCH/RBPJK targets. Examination of these selected genes using Allen Brain Map Transcriptomic Explorer with whole cortex and hippocampus $10 \times$ Database (Yao et al., 2021) evidenced that the majority (87\%) are neuronal-specific, validating our technical design. By narrowing our target validation on 5 genes with known association with $\mathrm{AD}$, we confirm that Nptx2, Npy, Pdch8, and TnC but not Scg2 are direct transcriptional targets of NOTCH/RBPJK. Based on the reported function of NPTX2 in AD related inhibitory circuit dysfunction (Xiao et al., 2017), and the observed role of NOTCH/RBPJK in regulating E/I balance, we confirmed that in the hippocampus of RbpjkcKO mice NPTX2 levels are strongly reduced causing also a downregulation of GLUR1. This is line with the role of neuronal pentraxins, NPs, as synaptic organizer which herds the specialization and maturation of excitatory synapses through the recruitment of AMPA receptors, GLUR1 (Lee et al., 2017) and GLUR4 (Sia et al., 2007). Besides the evidence that synaptic activity induces the expression of NPs (Leslie and Nedivi, 2011), we add that this upregulation is a result of NOTCH/RBPJK activation. NPTX2 has received particular attention as levels decline in the progression of $\mathrm{AD}$ and it represents one of the few differential biomarker for $A \beta$ resilience (Xiao et al., 2017). Our analysis in human AD brains shows a fluctuation in the expression of NPTX2 from a near to significant rise in mild-moderate AD as compared to cognitively normal controls to a subsequent decrease in severe $\mathrm{AD}$, perhaps indicating a neuronal response to $\mathrm{AD}$ early that is lost with advanced neurodegeneration. NPTX2 transcript levels associate with the canonical target $H E Y 1$, validating its identity as NOTCH/ RBPJK downstream gene. Interestingly, several of the identified NOTCH-dependent genes, DNER, HES5, HEY1, NPTX2, NPY, BDNF and $G A B R A 2 A$ display an upregulating trend in the mild-moderate stage of $\mathrm{AD}$ and a subsequent decline in the severe $\mathrm{AD}$ stage. This may signify mechanism in place to mitigate the effect of the E/I imbalance in the intermediate stage of the disease. On the other hand, the identified NOTCH/RBPJK target ANXA2, expressed in glia but also in neurons, is progressively reduced with the severity of the disease indicating a negative regulation of autophagy (Moreau et al., 2015) typically seen in astroglia and mislocalization of Tau in neurons (Gauthier-Kemper et al., 2018).

While the connectivity to Notch-signaling is provided in the animal study through the RNA-sequencing, the targeted RT-PCR on human specimen lacks to capture these dependencies, likely as a result of the ubiquitary presence of Notch signaling in the brain. 
Nevertheless, this is the first report detailing a number of novel NOTCH targets, with instrumental functions for synaptic scaling and plasticity which are lost in the progression of $\mathrm{AD}$, we recognize the limitation of this study based on the bulk approach. This makes singlecell resolution methods in human brain tissue imperative to unlock the cell-specific transcriptional maps associated with NOTCH activity. This is true also for other ubiquitary pathways such as Insulin that have been evoked in the pathogenesis of $\mathrm{AD}$ but have failed to provide functional outcomes instrumental for drug development. Finally, despite the fact that we have used a multicentric clinical cohort of AD brain cases, our power remains low due to the limited number of cases. These result as such limit our ability to make conclusive statements about the NOTCH/RBPJK signaling ensemble and appeals for consortium studies capable of enriching the datasets with the focus of shedding light on the driving mechanisms underlying $\mathrm{AD}$ pathogenesis, particularly for the sake of identifying disease-modifying targets to revert excitotoxic neurodegeneration in the early and intermediate stage of the disease.

Concluding, this study demonstrates for the first time that NOTCH/ RBPJK signaling in neurons has direct and indirect targets instrumental for synaptic plasticity substantiating previous work and supporting a role for this molecular cascade from E/I imbalance to neuronal demise.

Supplementary data to this article can be found online at https://doi. org/10.1016/j.mcn.2021.103657.

\section{CRediT authorship contribution statement}

Amalia Perna Conceptualization, Methodology, Formal analysis, Investigation, Writing - Original Draft, Visualization Swananda Marathe: Conceptualization, Methodology, Investigation Renè Dreos: Formal analysis Laurent Falquet: Formal analysis Hatice Akarsu: Formal analysis Lavinia Alberi: Conceptualization, Methodology, Resources, Writing - Review \& Editing, Supervision, Project administration, Funding acquisition.

\section{Declaration of competing interest}

The authors declare no competing financial interest.

\section{Acknowledgments}

This research was supported by the Swiss National Foundation (SNF163470; LA). We thank Valérie Tâche and Eva Martin for technical assistance. We acknowledge the help of the undergraduate students who contributed to this project: Daniel Berchtold and Simon April.

\section{References}

Alberi, L., Liu, S., Wang, Y., Badie, R., Smith-Hicks, C., Wu, J., Pierfelice, T.J., Abazyan, B., Mattson, M.P., Kuhl, D., Pletnikov, M., Worley, P.F., Gaiano, N., 2011. Activity-induced Notch Signaling in Neurons Requires Arc/Arg3.1 and Is Essential for Synaptic Plasticity in Hippocampal Networks.

Alberi, L., Hoey, S.E., Brai, E., Scotti, A.L., Marathe, S., 2013. Notch signaling in the brain: in good and bad times. Ageing Res. Rev. 12 (3), 801-814.

Ambrosini, G., Groux, R., Bucher, P., 2018. PWMScan: a fast tool for scanning entire genomes with a position-specific weight matrix. Bioinformatics 34 (14), 2483-2484.

Andersen, P., Uosaki, H., Shenje, L.T., Kwon, C., 2012. Non-canonical notch signaling: emerging role and mechanism. Trends Cell Biol. 22 (5), 257-265.

Alzheimer's disease facts and figures. Alzheimers Dement.16 (3),, 2020, 391-460.

Arumugam, T.V., Cheng, Y.-L., Choi, Y., Choi, Y.-H., Yang, S., Yun, Y.-K., Park, J.-S. Yang, D.K., Thundyil, J., Gelderblom, M., 2011. Others, evidence that -secretasemediated notch signaling induces neuronal cell death via the nuclear factor-B-Bcl-2interacting mediator of cell death pathway in ischemic stroke. Mol. Pharmacol. 80 (1), 23-31.

Arumugam, T.V., Baik, S.-H., Balaganapathy, P., Sobey, C.G., Mattson, M.P., Jo, D.-G., 2018. Notch signaling and neuronal death in stroke. Prog. Neurobiol. 165, 103-116.

Bausch, S.B., 2006. Potential roles for hyaluronan and CD44 in kainic acid-induced mossy fiber sprouting in organotypic hippocampal slice cultures. Neuroscience 143 (1), 339-350.

Brai, E., Marathe, S., Astori, S., Fredj, N.B., Perry, E., Lamy, C., Scotti, A., Alberi, L. 2015. Notch1 regulates hippocampal plasticity through interaction with the reelin pathway, glutamatergic transmission and CREB signaling. Front. Cell. Neurosci. 9, 447.
Buschler, A., Manahan-Vaughan, D., 2012. Brief environmental enrichment elicits metaplasticity of hippocampal synaptic potentiation in vivo. Front. Behav. Neurosci. $6,85$.

DeTure, M.A., Dickson, D.W., 2019. The Neuropathological Diagnosis of Alzheimer\&apos;s Disease.

Eden, E., Navon, R., Steinfeld, I., Lipson, D., Yakhini, Z., 2009. GOrilla: a tool for discovery and visualization of enriched GO terms in ranked gene lists. BMC Bioinformatics 10, 48.

Falo-Sanjuan, J., Bray, S.J., 2020. Decoding the notch signal. Develop. Growth Differ. 62 (1), 4-14.

Folch, J., Busquets, O., Ettcheto, M., Sánchez-López, E., Castro-Torres, R.D. Verdaguer, E., Garcia, M.L., Olloquequi, J., Casadesús, G., Beas-Zarate, C., et al., 2018. Memantine for the treatment of dementia: a review on its current and future applications. J. Alzheimers Dis. 62 (3), 1223-1240.

Gadhave, K., Kumar, D., Uversky, V.N., Giri, R., 2020. A Multitude of Signaling Pathways Associated With Alzheimer's Disease and Their Roles in AD Pathogenesis and Therapy, Med. Res. Rev.

Gauthier-Kemper, A., Alonso, M.S., Sündermann, F., Niewidok, B., Fernandez, M.-P., Bakota, L., Heinisch, J.J., Brandt, R., 2018. Annexins a2 and a6 interact with the extreme $\mathrm{n}$ terminus of tau and thereby contribute to tau's axonal localization. J. Biol. Chem. 293 (21), 8065-8076.

Gomazkov, O.A., 2015. How Do Signaling Molecules Organize Higher Brain Functions?.

Han, H., Tanigaki, K., Yamamoto, N., Kuroda, K., Yoshimoto, M., Nakahata, T., Ikuta, K., Honjo, T., 2002. Inducible Gene Knockout of Transcription Factor Recombination Signal Binding Protein-j Reveals Its Essential Role in T Versus B Lineage Decision.

Hemonnot, A.-L., Hua, J., Ulmann, L., Hirbec, H., 2019. Microglia in alzheimer disease: well-known targets and new opportunities. Front. Aging Neurosci. 11, 233.

Koopmans, F., van Nierop, P., Andres-Alonso, M., Byrnes, A., Cijsouw, T., Coba, M.P., Cornelisse, L.N., Farrell, R.J., Goldschmidt, H.L., Howrigan, D.P., Hussain, N.K., Imig, C., de Jong, A.P.H., Jung, H., Kohansalnodehi, M., Kramarz, B., Lipstein, N., Lovering, R.C., MacGillavry, H., Mariano, V., Mi, H., Ninov, M., OsumiSutherland, D., Pielot, R., Smalla, K.-H., Tang, H., Tashman, K., Toonen, R.F.G., Verpelli, C., Reig-Viader, R., Watanabe, K., van Weering, J., Achsel, T., Ashrafi, G., Asi, N., Brown, T.C., De Camilli, P., Feuermann, M., Foulger, R.E., Gaudet, P., Joglekar, A., Kanellopoulos, A., Malenka, R., Nicoll, R.A., Pulido, C., de JuanSanz, J., Sheng, M., Südhof, T.C., Tilgner, H.U., Bagni, C., Bayés, À., Biederer, T., Brose, N., Chua, J.J.E., Dieterich, D.C., Gundelfinger, E.D., Hoogenraad, C., Huganir, R.L., Jahn, R., Kaeser, P.S., Kim, E., Kreutz, M.R., McPherson, P.S. Neale, B.M., O'Connor, V., Posthuma, D., Ryan, T.A., Sala, C., Feng, G., Hyman, S.E., Thomas, P.D., Smit, A.B., Verhage, M., 2019. SynGO: an evidence-based, expertcurated knowledge base for the synapse. Neuron 103 (2), 217-234.e4.

Kopan, R., Ilagan, M.X.G., 2009. The canonical notch signaling pathway: unfolding the activation mechanism. Cell 137 (2), 216-233.

Kulakovskiy, I.V., Vorontsov, I.E., Yevshin, I.S., Sharipov, R.N., Fedorova, A.D. Rumynskiy, E.I., Medvedeva, Y.A., Magana-Mora, A., Bajic, V.B., Papatsenko, D.A., Kolpakov, F.A., Makeev, V.J., 2018. HOCOMOCO: towards a complete collection of transcription factor binding models for human and mouse via large-scale ChIP-seq analysis. Nucleic Acids Res. 46 (D1), D252-D259.

Lawrence, M., Gentleman, R., Carey, V., 2009. rtracklayer: An R Package for Interfacing With Genome Browsers.

Lee, S.-J., Wei, M., Zhang, C., Maxeiner, S., Pak, C., Botelho, S.C., Trotter, J., Sterky, F.H., Südhof, T.C., 2017. Presynaptic neuronal pentraxin receptor organizes excitatory and inhibitory synapses. J. Neurosci. 37 (5), 1062-1080.

Leslie, J.H., Nedivi, E., 2011. Activity-regulated genes as mediators of neural circuit plasticity. Prog. Neurobiol. 94 (3), 223-237.

Li, Y., Hibbs, M.A., Gard, A.L., Shylo, N.A., Yun, K., 2012. Genome-wide analysis of N1ICD/RBPJ targets in vivo reveals direct transcriptional regulation of wnt, SHH, and hippo pathway effectors by notch1. Stem Cells 30 (4), 741-752.

Lin, E.-J.D., Young, D., Baer, K., Herzog, H., During, M.J., 2006. Differential actions of NPY on seizure modulation via Y1 and Y2 receptors: evidence from receptor knockout mice. Epilepsia 47 (4), 773-780.

Liu, S., Wang, Y., Worley, P.F., Mattson, M.P., Gaiano, N., 2015. The canonical notch pathway effector RBP-J regulates neuronal plasticity and expression of GABA transporters in hippocampal networks. Hippocampus 25 (5), 670-678.

Mahata, S.K., Marksteiner, J., Sperk, G., Mahata, M., Gruber, B., Fischer-Colbrie, R., Winkler, H., 1992. Temporal Lobe Epilepsy of the Rat: Differential Expression of mRNAs of Chromogranin b, Secretogranin II, Synaptin/synaptophysin and p65 in Subfields of the Hippocampus.

Marathe, S., Liu, S., Brai, E., Kaczarowski, M., Alberi, L., 2015. Notch signaling in response to excitotoxicity induces neurodegeneration via erroneous cell cycle reentry. Cell Death Differ. 22 (11), 1775-1784.

Merico, D., Isserlin, R., Stueker, O., Emili, A., Bader, G.D., 2010. Enrichment map: a network-based method for gene-set enrichment visualization and interpretation. PLoS One 5 (11), e13984.

Montojo, J., Zuberi, K., Rodriguez, H., Kazi, F., Wright, G., Donaldson, S.L., Morris, Q. Bader, G.D., 2010. GeneMANIA Cytoscape Plugin: Fast Gene Function Predictions on the Desktop.

Moreau, K., Ghislat, G., Hochfeld, W., Renna, M., Zavodszky, E., Runwal, G., Puri, C., Lee, S., Siddiqi, F., Menzies, F.M., et al., 2015. Transcriptional regulation of annexin a2 promotes starvation-induced autophagy. Nat. Commun. 6 (1), 1-12.

Okochi, M., 2002. Presenilins mediate a dual intramembranous gamma-secretase cleavage of notch-1. EMBO J. 21 (20), 5408-5416.

Osborn, L.M., Kamphuis, W., Wadman, W.J., Hol, E.M., 2016. Astrogliosis: an integral player in the pathogenesis of Alzheimer\&apos;s disease. Prog. Neurobiol. 144 $121-141$. 
Otani, N., Nawashiro, H., Nomura, N., Fukui, S., Tsuzuki, N., Ishihara, S., Shima, K., 2003. A Role of Glial Fibrillary Acidic Protein in Hippocampal Degeneration After Cerebral Trauma or Kainate-induced Seizure.

Perna, A., Alberi, L.A., 2019. TF-ChIP method for tissue-specific gene targets. Front. Cell. Neurosci. 13, 95

Radtke, F., Ferrero, I., Wilson, A., Lees, R., Aguet, M., MacDonald, H.Robson, 2000. Notch1 Deficiency Dissociates the Intrathymic Development of Dendritic Cells and T Cells.

Redmond, L., Oh, S.R., Hicks, C., Weinmaster, G., Ghosh, A., 2000. Nuclear notch1 signaling and the regulation of dendritic development. Nat. Neurosci. 3 (1), 30-40.

Schlicker, A., Domingues, F.S., Rahnenführer, J., Lengauer, T., 2006. A new measure for functional similarity of gene products based on gene ontology. BMC Bioinformatics 7, 302.

Sia, G.-M., Béïque, J.-C., Rumbaugh, G., Cho, R., Worley, P.F., Huganir, R.L., 2007. Interaction of the n-terminal domain of the ampa receptor glur4 subunit with the neuronal pentraxin np1 mediates glur4 synaptic recruitment. Neuron 55 (1), 87-102.

Sprissler, R.S., Wagnon, J.L., Bunton-Stasyshyn, R.K., Meisler, M.H., Hammer, M.F., 2017. Altered gene expression profile in a mouse model of scn8a encephalopathy. Exp. Neurol. 288, 134-141.

Storey, J.D., Tibshirani, R., 2003. Statistical significance for genomewide studies. Proc. Natl. Acad. Sci. U. S. A. 100 (16), 9440-9445.

Subramanian, A., Tamayo, P., Mootha, V.K., Mukherjee, S., Ebert, B.L., Gillette, M.A., Paulovich, A., Pomeroy, S.L., Golub, T.R., Lander, E.S., Mesirov, J.P., 2005. Gene set enrichment analysis: a knowledge-based approach for interpreting genome-wide expression profiles. Proc. Natl. Acad. Sci. U. S. A. 102 (43), 15545-15550.

Supek, F., Bošnjak, M., Škunca, N., Šmuc, T., 2011. REVIGO summarizes and visualizes long lists of gene ontology terms. PLoS One 6 (7), e21800.

Tsien, J.Z., Chen, D.F., Gerber, D., Tom, C., Mercer, E.H., Anderson, D.J., Mayford, M., Kandel, E.R., Tonegawa, S., 1996. Subregion- and cell type-restricted gene knockout in mouse brain. Cell 87 (7), 1317-1326.

Tun, T., Hamaguchi, Y., Matsunami, N., Furukawa, T., Honjo, T., Kawaichi, M., 1994 Recognition Sequence of a Highly Conserved DNA Binding Protein RBP-Jx.

Varela, E.V., Etter, G., Williams, S., 2019. Excitatory-inhibitory Imbalance in Alzheimer\&apos;s Disease and Therapeutic Significance.

Wang, R., Reddy, P.H., 2017. Role of glutamate and nmda receptors in Alzheimer\&apos;s disease. J. Alzheimers Dis. 57 (4), 1041-1048.

Xiao, M.-F., Xu, D., Craig, M.T., Pelkey, K.A., Chien, C.-C., Shi, Y., Zhang, J., Resnick, S., Pletnikova, O., Pletnikova, O., Salmon, D., Brewer, J., Edland, S., Wegiel, J., Tycko, B., Savonenko, A., Reeves, R.H., Troncoso, J.C., McBain, C.J., Galasko, D. Worley, P.F., 2017. NPTX2 and cognitive dysfunction in alzheimer's disease. Elife 6.

Yao, Z., Nguyen, T.N., van Velthoven, C.T., Goldy, J., Sedeno-Cortes, A.E., Baftizadeh, F., Bertagnolli, D., Casper, T., Crichton, K., Ding, S.-L., et al., 2021. A taxonomy of transcriptomic cell types across the isocortex and hippocampal formation.

Yoon, K., Gaiano, N., 2005. Notch signaling in the mammalian central nervous system: insights from mouse mutants. Nat. Neurosci. 8 (6), 709-715.

Zheng, X.-Y., Zhang, H.-L., Luo, Q., Zhu, J., 2011. Kainic acid-induced neurodegenerative model: potentials and limitations. J. Biomed. Biotechnol. 2011, 457079. 